\title{
Evaluation of the Lidar/Radiometer Inversion Code (LIRIC) to determine microphysical properties of volcanic and desert dust
}

\author{
J. Wagner ${ }^{1}$, A. Ansmann ${ }^{1}$, U. Wandinger ${ }^{1}$, P. Seifert ${ }^{1}$, A. Schwarz ${ }^{1}$, M. Tesche ${ }^{2}$, A. Chaikovsky ${ }^{3}$, and O. Dubovik ${ }^{4}$ \\ ${ }^{1}$ Leibniz Institute for Tropospheric Research, Leipzig, Germany \\ ${ }^{2}$ Department of Environmental Science, Stockholm University, Stockholm, Sweden \\ ${ }^{3}$ Institute of Physics, National Academy of Science, Minsk, Belarus \\ ${ }^{4}$ Laboratory of Atmospheric Optics, Lille University 1, Villeneuve d'Ascq, France
}

Correspondence to: A. Ansmann (albert@tropos.de)

Received: 18 December 2012 - Published in Atmos. Meas. Tech. Discuss.: 25 January 2013

Revised: 13 June 2013 - Accepted: 13 June 2013 - Published: 22 July 2013

\begin{abstract}
The Lidar/Radiometer Inversion Code (LIRIC) combines the multiwavelength lidar technique with sun/sky photometry and allows us to retrieve vertical profiles of particle optical and microphysical properties separately for finemode and coarse-mode particles. After a brief presentation of the theoretical background, we evaluate the potential of LIRIC to retrieve the optical and microphysical properties of irregularly shaped dust particles. The method is applied to two very different aerosol scenarios: a strong Saharan dust outbreak towards central Europe and an Eyjafjallajökull volcanic dust event. LIRIC profiles of particle mass concentrations for the coarse-mode as well as for the non-spherical particle fraction are compared with results for the non-spherical particle fraction as obtained with the polarization-lidar-based POLIPHON method. Similar comparisons for fine-mode and spherical particle fractions are presented also. Acceptable agreement between the different dust mass concentration profiles is obtained. LIRIC profiles of optical properties such as particle backscatter coefficient, lidar ratio, Ångström exponent, and particle depolarization ratio are compared with direct Raman lidar observations. Systematic deviations between the LIRIC retrieval products and the Raman lidar measurements of the desert dust lidar ratio, depolarization ratio, and spectral dependencies of particle backscatter and lidar ratio point to the applied spheroidal-particle model as main source for these uncertainties in the LIRIC results.
\end{abstract}

\section{Introduction}

The recent Icelandic volcanic eruptions in 2010 and 2011 emphasized the importance of remote-sensing methods that allow for the separation of fine-mode and coarse-mode particles in the troposphere as a function of height (Ansmann et al., 2011a, 2012) in order to quantify particle mass concentrations in lofted desert and volcanic dust layers. From the point of view of atmospheric research, there is a strong request for vertically resolved observations of optical and microphysical properties of atmospheric aerosols in order to improve our understanding of direct and indirect effects of aerosols on climate-relevant processes. The aerosol influence can be very different in the polluted boundary layer and in the free troposphere due to different aerosol lifetimes, transport ways and ranges, and interaction with low, midlevel, and high clouds.

To address these needs efforts are presently undertaken in the framework of the European Aerosols, Clouds and Trace gases Research Infrastructure Network (ACTRIS) to make complementary use of different measurement techniques such as lidar (aerosol vertical profiling) and sun/sky photometry (spectrally resolved optical aerosol characterization) at combined European Aerosol Research Lidar Network (EARLINET) and Aerosol Robotic Network (AERONET) stations. The recently developed Lidar/Radiometer Inversion Code (LIRIC) was designed as a universal code for processing lidar/photometer network data, applicable to many different instrumental conditions and technical approaches. As will be outlined in Sect. 2, LIRIC uses profiles of 
elastic-backscatter lidar return signals at 355, 532, and $1064 \mathrm{~nm}$ and, as a priori assumptions, AERONET photometer retrieval products (column-integrated particle size distributions, composition, complex refractive index, and particle shape) (Chaikovsky et al., 2008, 2012). Products of this synergistic data analysis are height profiles of particle backscatter and extinction coefficients at the three wavelengths, and particle volume and mass concentration profiles separately for fine-mode and coarse-mode particles. The main goal of the LIRIC approach is to create a height-resolved data set of particle optical and microphysical properties that is in full agreement with the respective column-integrated findings from the sun/sky photometer observations. The method has been developed in a cooperation between the Institute of Physics Minsk (Belarus) and the Laboratoire d'Optique Atmosphérique Lille (France) (Chaikovsky et al., 2008, 2012). The recently introduced Generalized Aerosol Retrieval from Radiometer and Lidar Combined Data (GARRLiC) (Lopatin et al., 2013) can be regarded as an extended version of LIRIC. The GARRLiC concept pursues an even deeper synergy of lidar and radiometer data in the retrievals, e.g., by using the lidar profile information to improve the AERONET retrievals.

There have been similar attempts to combine passive spaceborne remote sensing of aerosols with lidar aerosol profiling. Léon et al. (2003) and Kaufman et al. (2003a,b) combined lidar observations of height profiles of particle backscattering with column-integrated spectral radiances measured with MODIS (Moderate Resolution Imaging Spectroradiometer) to retrieve profiles of particle optical properties that are consistent with the microphysical properties from the MODIS observations. The third group of retrieval methods to derive microphysical particle properties are solely based on multiwavelength lidar observations of particle extinction and backscatter coefficients (Müller et al., 1999; Veselovskii et al., 2002; Böckmann et al., 2005). Recently these inversion techniques were extended to cover also desert dust observations and dust/smoke/sulfate aerosol mixtures (Veselovskii et al., 2010; Müller et al., 2013).

All these retrieval methods above are based on the assumption that the optical properties of the non-spherical, irregularly shaped coarse dust particles (desert dust, volcanic dust) can be sufficiently well described by assuming an ensemble of randomly oriented spheroidal dust particles with homogeneous mineralogical composition throughout the dust particle size distribution. However, prolate and oblate particles of different size are only approximations of the true shape of mineral dust particles. The exact shape of the dust particles cannot be described in this way. Ellipsoids have smooth surfaces, in contrast to the dust particles. Inclusions of various minerals in the dust grains and heterogeneous chemical composition are also not accounted for (Müller et al., 2013). Gasteiger et al. (2011a) pointed out that in addition to the shape effects, the assumption on the mineralogical composition (i.e., on the external and internal mixture of lightabsorbing and non-absorbing dust particles) also have a very sensitive influence on the backscattering efficiency of dust particles.

The concept of describing the non-spherical component as an ensemble of randomly oriented spheroids with sizeindependent aspect-ratio (length-to-width-ratio) distribution has been successfully employed in the operational retrieval algorithm of AERONET (Dubovik et al., 2006); however, the central question remains: is that model also appropriate for lidar applications that are based on backscattering by particles at exactly $180^{\circ}$ scattering angle? The lidar inversion methods mentioned above were developed to retrieve microphysical properties of spherical aerosol particles (urban haze, fire smoke). Müller et al. (2013) state that the main reason for not using the spheroidal-particle model for mineral dust data is rooted in the poor understanding of how to describe the $180^{\circ}$ light-scattering properties of particles of irregular (non-spherical) shape. The authors further state that there is still a need for theoretical models that link specific features of a particle's shape to its specific optical properties such as the measurable shape-sensitive particle extinction-tobackscatter ratio (lidar ratio) and the particle depolarization ratio. The lidar observations performed during the Saharan Mineral Dust Experiment (SAMUM) campaigns corroborate that the spheroidal-particle model may not be adequate for lidar applications (Müller et al., 2010, 2012; Ansmann et al., 2011b; Gasteiger et al., 2011a).

Here we investigate the potential of LIRIC to retrieve profiles of desert and volcanic dust optical properties such as the lidar ratio and depolarization ratio as well as microphysical properties such as particle volume and mass concentrations. Fortunately, independent remote-sensing methods are available that enable us to directly and simultaneously measure lidar ratio and depolarization ratio profiles by using the Raman/polarization lidar technique and to retrieve particle volume and mass concentrations of fine-mode and coarsemode particles by means of the polarization lidar photometer network (POLIPHON) method (Ansmann et al., 2011a, 2012). These methods are also explained in Sect. 3. The POLIPHON technique is based on the measured height profile of the particle depolarization ratio to separate coarse dust from the residual aerosol particles, and does not make use of the spheroidal-particle model. However, the POLIPHON products contain uncertainties as well, especially for mixed aerosol cases, as will be discussed in Sect. 4 .

We focus on two cases with aerosol layers containing a considerable amount of irregularly shaped coarse-mode particles. The first case refers to a strong Saharan dust outbreak towards Europe in May 2008. The second case covers the aerosol conditions after the eruption of the Icelandic volcano Eyjafjallajökull in April 2010. Section 2 describes the measurement systems. The LIRIC method is explained in Sect. 3. In addition, the basic idea of the POLIPHON method is briefly outlined. In Sect. 4, results are presented and discussed. Section 5 contains summarizing and concluding remarks. 


\section{Measurement systems}

\subsection{Raman lidar MARTHA}

The multiwavelength Raman lidar MARTHA (Multiwavelength Atmospheric Raman lidar for Temperature, Humidity, and Aerosol profiling) is used for regular aerosol observations at the EARLINET station of Leipzig (Mattis et al., 2004). It provides height profiles of particle backscatter and extinction coefficients, as well as lidar ratios and volume and particle depolarization ratios (Ansmann et al., 1992, 2011a). Because Raman lidar signals are used (in addition to elasticbackscatter signals), the method works best during darkness in the absence of strong sky background radiation. However, during events with optically dense aerosol layers, the Ramanlidar method can even be applied during daylight hours, as will be shown in Sect. 4.

For LIRIC, the elastically backscattered signals at the three transmitted wavelengths of 355, 532, and $1064 \mathrm{~nm}$ and the cross-polarized signal at $532 \mathrm{~nm}$ are used. LIRIC was originally designed for the analysis of lidar measurements at the three wavelengths of 355, 532, and $1064 \mathrm{~nm}$. It has been extended to cover polarization lidar observations as well. MARTHA transmits linearly polarized laser light at $532 \mathrm{~nm}$ and has two channels to measure the cross-polarized lidar return signal $P^{\perp}(\lambda, z)$ (the polarization-sensitive filter element is aligned orthogonal to the plane of laser beam polarization) and the total (cross and parallel-polarized) backscatter light $P^{\perp}(\lambda, z)+P^{\|}(\lambda, z)$ with a second channel. From these signals the depolarization ratio (introduced in the next section) can be determined. Non-spherical particles such as desert or volcanic dust particles cause significant depolarization (a significant signal $P^{\perp}$ ), whereas spherical particles and even fine-mode urban haze particles produce almost no cross-polarized backscatter.

The Raman signals are not used in the LIRIC scheme. However, the products of the Raman lidar measurements (backscatter, extinction, lidar ratio, depolarization ratio) are used in the LIRIC validation study. A direct comparison between the LIRIC and Raman lidar profiles provides the best opportunity to validate the LIRIC efforts.

For an optimum application of the LIRIC method, i.e., combining spectral tropospheric column with tropospheric profile information, it is necessary that the lidar covers almost the entire tropospheric column (as seen by the photometer) with profile observations. However, the incomplete overlap between the transmitted laser beams and the receiver field of view (RFOV) prohibits the measurement of reliable lidar return signals in the near range (usually up to a few $100 \mathrm{~m}$; in the case of MARTHA up to a few kilometers because of the large telescope). The overlap function of our lidar is routinely and regularly determined and checked during clear nights with low aerosol amount by means of the method discussed by Wandinger and Ansmann (2002). The overlap profile is then applied to the aerosol lidar observations and allows us to correct the overlap effect usually down to heights of 500 $1000 \mathrm{~m}$ above the lidar. Under favorable conditions (as for the Saharan dust case presented here), the overlap correction is reliable down to low minimum measurement heights of $150 \mathrm{~m}$. Because the overlap effect may change from one to another lidar alignment, which is routinely done at the beginning of each long-lasting lidar measurement session, different experimentally determined overlap profiles are used to check and quantify the impact of potential overlap uncertainties on the LIRIC retrieval accuracy.

\subsection{Sun/sky photometer}

LIRIC makes use of photometer-derived particle parameters that link the particle volume concentration to particle backscattering and extinction at 355, 532, and $1064 \mathrm{~nm}$. The AERONET sun/sky photometers detect direct sun, aureole, and sky radiance (Holben et al., 1998). At the Leipzig station, direct sun radiation is measured in eight channels centered at wavelengths of $339,379,441,501,675,869,940$, 1021 , and $1638 \mathrm{~nm}$. Sky radiation is obtained in four bands centered at 441, 675, 869, and $1021 \mathrm{~nm}$. From direct sun measurements the aerosol (particle) optical thickness (AOT) and the Angström exponent that describes the AOT wavelength dependence is derived. Sun and sky radiance observations are used for inversion algorithms to retrieve microphysical aerosol properties such as the volume particle size distribution for fine and coarse mode (Dubovik and King, 2000; Dubovik et al., 2006). The AERONET data analysis code searches for the minimum in the bimodal particle volume size distribution in the particle radius range of 0.194 to $0.576 \mu \mathrm{m}$. The found minimum is used as a separation radius between fine-mode and coarse-mode particles. The complex refractive index and the contribution of spherical particles to the fine-mode and coarse-mode particle fractions are determined in addition. The wavelength-dependent refractive index is the same for both fine and coarse particles. In summary, from the retrieved information, AOTs, particlescattering phase functions, asymmetry parameters, and column volume and surface-area concentrations of the particles are derived for spherical and non-spherical particles of the fine-mode and coarse-mode fractions (Dubovik et al., 2006). In cases without sky radiance observations, the AOTs and the column volume concentrations for fine and coarse mode are derived from the spectral dependence of measured AOT (O'Neill et al., 2003). The case studies in Sect. 4 are based on the Dubovik method.

The inversion of AERONET sky radiance measurements to obtain microphysical aerosol properties is well established (Dubovik and King, 2000; Dubovik et al., 2002, 2006). Besides these products, column values of the volume-specific backscatter and extinction coefficients can be estimated separately for spherical and non-spherical particles in the fine mode as well as in the coarse mode (fine mode, coarse mode 
without hyphens). These volume-specific backscatter and extinction values are important input data for LIRIC.

The spheroidal-particle model as introduced by Dubovik et al. (2006) is successfully applied to the inversion of AERONET sun/sky photometer data to properly derive microphysical properties of desert dust. However, the way the spheroidal-particle model influences the AERONET retrievals of dust properties is quite different from the way the spheroidal-particle model influences lidar applications and therefore the LIRIC results. In the case of AERONET, the complete phase function is fitted to the almucantar skybrightness data such that the phase function reproduces the almucantar data. In contrast, lidar backscatter data are representative of the sky brightness at just one scattering angle of exactly $180^{\circ}$. Whether the spheroidal-particle model is applicable to lidar observations remains an open question, as discussed in the introduction. Uncertainties in the estimation of volume-specific backscatter and extinction coefficients, required for LIRIC, arise also from the fact that sun/sky photometer measurements of almucantar usually end at a $150^{\circ}$ scattering angle. The AERONET model was extended to a phase function angle of $173^{\circ}$ on the basis of laboratory measurements of light scattering by dust (Volten et al., 2001). Direct observations of the sky brightness at $180^{\circ}$ scattering angle cannot be made, so all lidar-backscatter-related AERONET values are model-based quantities.

\section{Method}

\subsection{Data preparation and processing}

The basic structure of LIRIC is shown in Fig. 1. In our study we used the LIRIC version from autumn 2012. The lidar database for LIRIC consists of background-corrected, elastic-backscatter lidar signals $P\left(\lambda_{j}, z_{i}\right)$ for different laser wavelengths $\lambda_{j}$ :

$$
\begin{aligned}
P\left(\lambda_{j}, z_{i}\right) & =E_{0}\left(\lambda_{j}\right) \frac{O\left(\lambda_{j}, z_{i}\right)}{z_{i}^{2}}\left[\beta_{\mathrm{aer}}\left(\lambda_{j}, z_{i}\right)+\beta_{\mathrm{mol}}\left(\lambda_{j}, z_{i}\right)\right] \\
& \times \exp \left\{-2 \int_{0}^{z_{i}}\left[\alpha_{\mathrm{aer}}\left(\lambda_{j}, z\right)+\alpha_{\mathrm{mol}}\left(\lambda_{j}, z\right)\right] \mathrm{d} z\right\} .
\end{aligned}
$$

$E_{0}$ is the system constant and considers, e.g., the outgoing laser pulse energy, collection area of the telescope, optical efficiencies of the transmitter and receiver units, photon detection efficiency, and vertical thickness $\Delta z$ of the backscattering range cell. $O\left(\lambda_{j}, z_{i}\right)$ describes the incomplete overlap of the laser beam for wavelength $\lambda_{j}$ with the RFOV. $z_{i}$ denotes the vertical range between the lidar and the backscattering range cell. The near-range measurements are influenced by the changing laser-beam RFOV overlap. This effect is corrected by use of measured overlap functions $O\left(\lambda_{j}, z_{i}\right)$ as mentioned in Sect. 2.1. $\beta_{\text {aer }}$ and $\beta_{\text {mol }}$ are the particle and
Rayleigh backscatter coefficients and $\alpha_{\text {aer }}$ and $\alpha_{\text {mol }}$ the particle and Rayleigh extinction coefficients, respectively. Besides the three elastic-backscatter signals, the cross-polarized lidar return at $\lambda_{2}=532 \mathrm{~nm}$

$$
\begin{aligned}
P^{\perp}\left(\lambda_{2}, z_{i}\right) & =E_{0}\left(\lambda_{2}\right) \frac{O\left(\lambda_{2}, z_{i}\right)}{z_{i}^{2}}\left[\beta_{\text {aer }}^{\perp}\left(\lambda_{2}, z_{i}\right)+\beta_{\mathrm{mol}}^{\perp}\left(\lambda_{2}, z_{i}\right)\right] \\
& \times \exp \left\{-2 \int_{0}^{z_{i}}\left[\alpha_{\mathrm{aer}}\left(\lambda_{2}, z\right)+\alpha_{\mathrm{mol}}\left(\lambda_{2}, z\right)\right] \mathrm{d} z\right\}(2)
\end{aligned}
$$

is used.

After range and overlap correction the four signals are averaged over a given time period (of minutes to hours, depending on the variability of the aerosol conditions) to increase the signal-to-noise ratio. The corrected lidar signals

$P_{\mathrm{cor}}^{p}\left(\lambda_{j}, z_{i}\right)=\frac{P^{p}\left(\lambda_{j}, z_{i}\right) z_{i}^{2}}{O\left(\lambda_{j}, z_{i}\right)}$

form the basic lidar input data set in the LIRIC data analysis. Here $P^{p}\left(\lambda_{j}, z_{i}\right)$ with $p=\|+\perp$ or $p=\perp$ denotes the total backscatter signal and the cross-polarized signal (for $\lambda=532 \mathrm{~nm}$ ), respectively. For simplicity, we omit index $p$ (as in Eq. 1) when $p=\|+\perp$.

The minimum measurement height $z_{N_{0}}$ and the reference height $z_{N}$ must be defined. For heights below $z_{N_{0}}$, the retrieval assumes constant microphysical and heightindependent particle backscatter and extinction conditions as large as the values observed at the minimum measurement height (Mattis et al., 2004). Above $z_{N}$ the contribution of aerosol particles to the AOT is assumed to be negligible.

The following quantities are then introduced in the LIRIC procedure (see Fig. 1, green box):

$$
\begin{aligned}
L^{* p}\left(\lambda_{j}, z_{n}\right) & =\frac{P_{\mathrm{cor}}^{p}\left(\lambda_{j}, z_{n}\right)}{P_{\mathrm{cor}}^{p}\left(\lambda_{j}, z_{N}\right)}\left[\beta_{\mathrm{aer}}^{p}\left(\lambda_{j}, z_{N}\right)+\beta_{\mathrm{mol}}^{p}\left(\lambda_{j}, z_{N}\right)\right] \\
& \times \exp \left[-2 \sum_{i=N}^{n+1} \alpha_{\mathrm{mol}}\left(\lambda_{j}, z_{i}\right) \Delta z\right] \\
& =\left[\beta_{\mathrm{aer}}^{p}\left(\lambda_{j}, z_{n}\right)+\beta_{\mathrm{mol}}^{p}\left(\lambda_{j}, z_{n}\right)\right] \\
& \times \exp \left[2 \sum_{i=N}^{n+1} \alpha_{\mathrm{aer}}\left(\lambda_{j}, z_{i}\right) \Delta z\right]
\end{aligned}
$$

where the vertical range cell $\Delta z$ describes the range resolution of the lidar measurement. $L^{*}\left(\lambda_{j}, z_{n}\right)$ and $L^{* \perp}\left(\lambda_{2}, z_{n}\right)$ can be easily computed from the measured signal ratios by using height profiles of Rayleigh backscatter and extinction coefficients. The actual molecular optical properties are obtained from atmospheric temperature and pressure profiles by using a standard atmosphere model, information from a nearby radiosonde, or numerical weather prediction products. In this study, we applied the US standard atmosphere model and adjusted it to actual surface temperature and pressure observations. The cross-polarized Rayleigh backscatter coefficient $\beta_{\mathrm{mol}}^{\perp}$ contributes $<1 \%$ to the total molecular backscatter coefficient. Negligible particle depolarization 


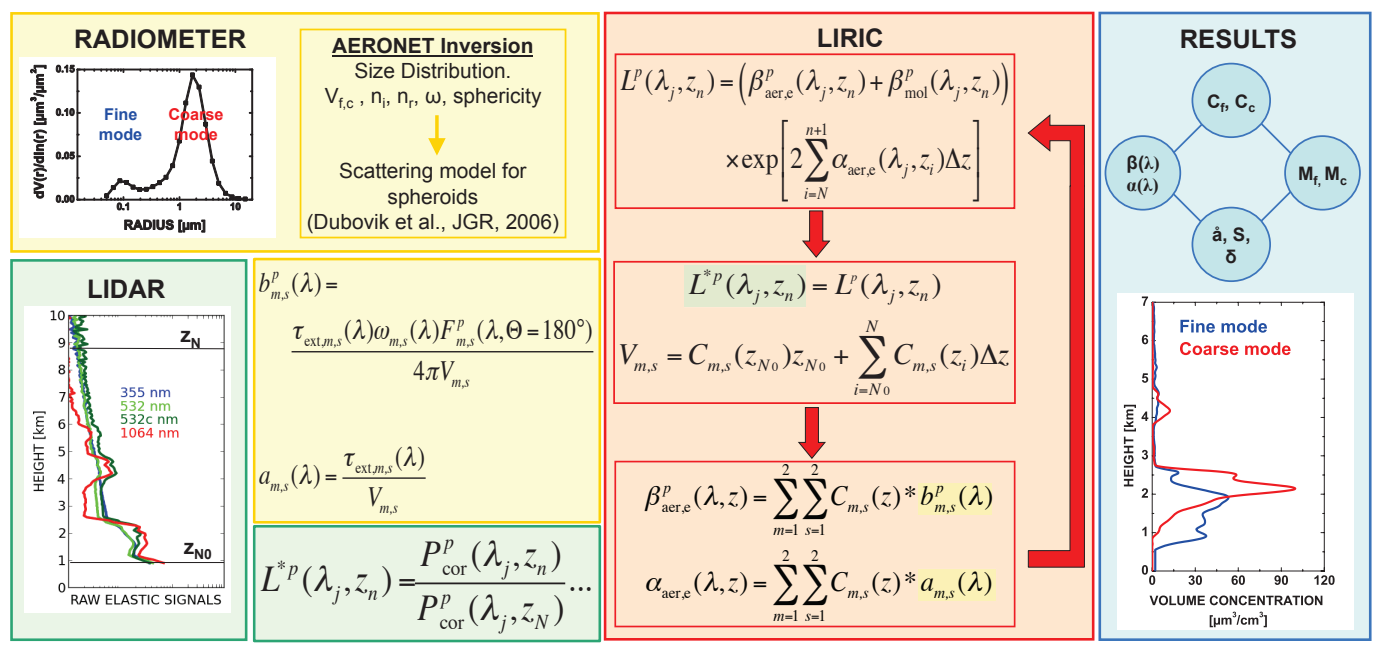

Fig. 1. Basic structure of LIRIC. Photometric information (radiometer, top yellow box) is used to retrieve height-independent (column) volume-specific backscatter and extinction coefficients $b_{m, s}$ and $a_{m, s}$ (center yellow box) for spherical $(s=1)$ and non-spherical particles $(s=2)$ of the fine mode $(m=\mathrm{f})$ and coarse mode $(m=\mathrm{c})$. A lidar signal term $L$ (orange box, top) can be calculated with LIRIC by using profiles of backscatter and extinction coefficients (orange box, bottom) that, in turn, are calculated from the volume-specific coefficients $b_{m, s}$ and $a_{m, s}$ and profiles of particle volume concentration $C_{m, s}(z)$. Deviations between the observed lidar signal term $L^{*}$ (green box) and the LIRIC expression $L$ are minimized in order to retrieve optimized $C_{m, s}(z)$ profiles (orange box, center). As a constraint, the integrals of the $C_{m, s}(z)$ profiles must match the respective column values $V_{m, s}$ as observed with AERONET photometer (orange box, center). LIRIC products (blue box) are profiles of particle optical properties (e.g., backscatter and extinction profiles, Ångström exponents, lidar and depolarization ratios) and microphysical properties (e.g., volume concentrations $C_{\mathrm{f}}$ and $C_{\mathrm{c}}$ as shown as profiles). The mass concentrations $M_{\mathrm{f}}$ and $M_{\mathrm{c}}$ for fine and coarse mode, respectively, are not LIRIC products.

$\left(\beta_{\mathrm{aer}}^{\perp}=0\right)$ is assumed at the reference height $z_{N}$. As a LIRIC start value at $z_{N}$, we assume a backscatter ratio of total (particle + Rayleigh) to Rayleigh backscattering of 1.1 at $z_{N}$ for all three wavelengths. However, the final backscatter and extinction profiles may not show these backscatter ratios of 1.1 at height $z_{N}$ at the end of the LIRIC data analysis. The LIRIC code is designed as a least-square-method-based statistically optimized retrieval procedure (Dubovik and King, 2000; Dubovik, 2004) as explained below, and searches for lidar profiles of particle optical and microphysical properties that best match the AERONET column-integrated findings. The calculation of $L^{*}\left(\lambda_{j}, z_{n}\right)$ and $L^{* \perp}\left(\lambda_{2}, z_{n}\right)$ starts from $z_{n}=z_{N-1}$ downward towards the minimum measurement height $z_{N_{0}}$ with a resolution of $15 \mathrm{~m}$.

Equation (4) shows that $L^{*}\left(\lambda_{j}, z_{n}\right)$ and $L^{* \perp}\left(\lambda_{2}, z_{n}\right)$ are mainly determined by height profiles of particle optical properties. These aerosol profiles are also estimated by means of aerosol products retrieved from the photometer observations. Comparing these profiles to the lidar measurements allows us to retrieve profiles of the particle volume concentrations. For this task, the expressions $L\left(\lambda_{j}, z_{n}\right)$ and $L^{\perp}\left(\lambda_{2}, z_{n}\right)$ similar to $L^{*}\left(\lambda_{j}, z_{n}\right)$ and $L^{* \perp}\left(\lambda_{2}, z_{n}\right)$ from Eq. (4) are introduced (see Fig. 1, orange box):

$$
\begin{aligned}
L^{p}\left(\lambda_{j}, z_{n}\right) & =\left[\beta_{\mathrm{aer}, \mathrm{e}}^{p}\left(\lambda_{j}, z_{n}\right)+\beta_{\mathrm{mol}}^{p}\left(\lambda_{j}, z_{n}\right)\right] \\
& \times \exp \left[2 \sum_{i=N}^{n+1} \alpha_{\mathrm{aer}, \mathrm{e}}\left(\lambda_{j}, z_{i}\right) \Delta z\right] .
\end{aligned}
$$

The particle backscatter and extinction coefficients $\beta_{\text {aer,e }}$ and $\alpha_{\text {aer,e }}$ (index e for estimate from photometer observations), respectively, are defined as

$$
\begin{aligned}
\beta_{\text {aer, } \mathrm{e}}(\lambda, z) & =C_{\mathrm{f}, 1}(z) b_{\mathrm{f}, 1}(\lambda)+C_{\mathrm{f}, 2}(z) b_{\mathrm{f}, 2}(\lambda) \\
& +C_{\mathrm{c}, 1}(z) b_{\mathrm{c}, 1}(\lambda)+C_{\mathrm{c}, 2}(z) b_{\mathrm{c}, 2}(\lambda), \\
\beta_{\mathrm{aer}, \mathrm{e}}^{\perp}(\lambda, z) & =C_{\mathrm{f}, 2}(z) b_{\mathrm{f}, 2}^{\perp}(\lambda)+C_{\mathrm{c}, 2}(z) b_{\mathrm{c}, 2}^{\perp}(\lambda), \\
\alpha_{\mathrm{aer}, \mathrm{e}}(\lambda, z) & =C_{\mathrm{f}, 1}(z) a_{\mathrm{f}, 1}(\lambda)+C_{\mathrm{f}, 2}(z) a_{\mathrm{f}, 2}(\lambda) \\
& +C_{\mathrm{c}, 1}(z) a_{\mathrm{c}, 1}(\lambda)+C_{\mathrm{c}, 2}(z) a_{\mathrm{c}, 2}(\lambda)
\end{aligned}
$$

with the particle volume concentrations $C_{m, s}(z)$ for particle mode $m$ (index $\mathrm{f}$ for fine mode and index c for coarse mode) and particle shape parameter $s$ with $s=1$ for spherical particles and $s=2$ for non-spherical particles. $C_{m, s}(z)$ are the variables that have to be optimized in the LIRIC data analysis. The procedure is outlined in detail in Chaikovsky et al. $(2008,2012)$ and Wagner (2012). In Eqs. (6)-(8), the column mean values of the volume-specific particle backscatter coefficients $b$ and $b^{\perp}$ and extinction coefficient $a$ are defined as (see Fig. 1, yellow boxes to the left)

$b_{m, s}^{p}(\lambda)=\frac{\tau_{\mathrm{ext}, m, s}(\lambda) \omega_{m, s}(\lambda) F_{m, s}^{p}\left(\lambda, \Theta=180^{\circ}\right)}{4 \pi V_{m, s}}$,

with

$F_{m, s}\left(\lambda, \Theta=180^{\circ}\right)=F_{11, m, s}\left(\lambda, \Theta=180^{\circ}\right)$, 


$$
\begin{aligned}
F_{m, 2}^{\perp}\left(\lambda_{2}, \Theta=180^{\circ}\right) & =\frac{1}{2}\left[F_{11, m, 2}\left(\lambda_{2}, \Theta=180^{\circ}\right)\right. \\
& \left.-F_{22, m, 2}\left(\lambda_{2}, \Theta=180^{\circ}\right)\right],
\end{aligned}
$$

and

$a_{m, s}(\lambda)=\frac{\tau_{\mathrm{ext}, m, s}(\lambda)}{V_{m, s}}$.

$F_{11}$ and $F_{22}$ are the first and second diagonal elements of the scattering matrix, respectively; $\tau_{\text {ext }}$ denotes the extinction optical thickness, and $\omega$ the single-scattering albedo. From photometric measurements (see Fig. 1, yellow box) the retrieved fine-mode and coarse-mode volume concentrations $V_{m, s}$, the complex refractive index (real part $n_{\mathrm{r}}$, imaginary part $n_{\mathrm{i}}$ ), the size distribution, and the volume fractions of spherical particles (denoted as sphericity in the AERONET database) are required to solve Eqs. (9)-(12). These quantities are obtained by means of the AERONET inversion algorithm. The nonspherical particles are described with the spheroidal-particle model after Dubovik et al. (2006).

Several simplifying assumptions are made. The refractiveindex characteristics are the same for fine and coarse particles. The ratio of spherical to spheroidal particles (in terms of column volume concentration) is also assumed to be the same for fine mode and coarse mode. However, the ratio can vary with height in the case of coarse-mode particles in accordance with the vertical distribution of non-spherical particles as indicated by the cross-polarized $532 \mathrm{~nm}$ backscatter signal. The ratio of spherical to spheroidal particles is heightindependent for fine-mode particles in order to keep the set of input parameters as small as possible. Under the assumption of randomly oriented spheroids in the particle mixture, $F_{11}, F_{22}, \tau_{\mathrm{ext}}$, and $\omega$ are provided for the lidar wavelengths by solving the vector radiative-transfer equation for a planeparallel multilayered atmosphere (Dubovik et al., 2006).

These simplifications may introduce considerable uncertainties, e.g., when spherical sulfate particles (fine mode) are present in the vertical column together with irregularly shaped volcanic dust particles (coarse mode). In this case, the refractive-index characteristics as well as the ratio of spherical to non-spherical particles are very different for fine and coarse particle fractions. Such a situation occurred after the Eyjafjallajökull volcanic eruption, and is discussed in the next section.

It remains to be mentioned that $b_{m, s}(\lambda)$ can be expressed by $a_{m, s}(\lambda) / S_{m, s}(\lambda)$ with the extinction-to-backscatter ratio (lidar ratio)

$S_{m, s}(\lambda)=\frac{4 \pi}{\omega_{m, s}(\lambda) F_{m, s}\left(\lambda, \Theta=180^{\circ}\right)}$.

The lidar ratio is an essential lidar parameter in the characterization of aerosol particle mixtures and types (Müller et al., 2007).

As mentioned, LIRIC is based on the least-square method (LSM) for the statistically optimized inversion of multisource data (Dubovik and King, 2000; Dubovik, 2004). It is out of the scope of this paper to describe the entire LIRIC data-processing scheme in detail. As part of the LIRIC optimization process the difference between the AERONETrelated expression $L^{p}\left(\lambda_{j}, z_{n}\right)$ and the lidar-derived expression $L^{* p}\left(\lambda_{j}, z_{n}\right)$ is minimized with respect to the particle volume concentrations $C_{m, s}$ (Fig. 1, orange box, center). Also, the photometer-derived column volume concentrations $V_{m, s}$ must agree with the corresponding integrals over the respective concentration profiles (Fig. 1, orange box, center):

$V_{m, s}=C_{m, s}\left(z_{N_{0}}\right) z_{N_{0}}+\sum_{i=N_{0}}^{N}\left[C_{m, s}\left(z_{i}\right)\right] \Delta z$.

Here, $C_{m, s}\left(z_{N_{0}}\right) z_{N_{0}}$ describes the contribution of the lowermost tropospheric layer (below the lowermost lidar measurement height $z_{N_{0}}$ ) to the volume concentration profile. For heights $<z_{N_{0}}$ the values are set constant and equal to the value at $z_{N_{0}}$.

The LSM-based statistical retrieval procedure requires covariance matrices of the lidar signal measurement errors (as a function of height). Details to the signal noise estimations for the observation cases shown here are given by Wagner (2012). To assure optimized profiles, the optimization process is performed within the error margins following principles of statistical estimation theory (Eadie et al., 1971). More information about the LIRIC data analysis can be found in Chaikovsky et al. $(2008,2012)$ and Wagner (2012).

To characterize the uncertainties in the LIRIC results the input parameters are varied. In Sect. 4, only errors are shown (as error bars) that originate from the LIRIC data procedure itself and the related input (regularization parameters). To obtain a characteristic error introduced by the LIRIC method, 5-10 runs were performed with realistic but well selected regularization parameter sets. These results were used in the estimation of the standard deviation of the entire uncertainty range (of possible LIRIC solutions).

Retrieval uncertainties caused by uncertainties in the input lidar profiles via uncertainties in the overlap correction, by selecting the minimum und maximum height of the LIRIC vertical range, and uncertainties in the particle backscatter coefficient at the reference height are discussed in Sect. 4 as well. However, the reference height is chosen in a range where particle backscattering does not contribute much to the lidar signal so that the impact on the uncertainty of the LIRIC results is low. The minimum height is selected such that the overlap correction above this height is trustworthy so that the influence of overlap correction uncertainties is kept as low as possible. The minimum measurement height is typically set into the lower to central part of the well-mixed boundary layer. The aerosol concentrations below the minimum height are assumed to be height-independent in the wellmixed layer, and the impact of this assumption on the retrieval uncertainty should therefore be small. In other words, these parameters are already optimized during the lidar signal 
preparation phase, and values other than the chosen lidar data parameters would lead to worse and usually unreasonable results in terms of backscatter and extinction profile structures, and can thus easily be sorted out.

Finally, the mass concentrations $M_{\mathrm{f}}(z)$ and $M_{\mathrm{c}}(z)$ for finemode and coarse-mode particles, respectively, can be calculated from the particle volume concentrations $C_{m, s}(z)$ :

$$
\begin{aligned}
& M_{\mathrm{f}}(z)=\rho_{1} C_{\mathrm{f}, 1}(z)+\rho_{2} C_{\mathrm{f}, 2}(z), \\
& M_{\mathrm{c}}(z)=\rho_{1} C_{\mathrm{c}, 1}(z)+\rho_{2} C_{\mathrm{c}, 2}(z) .
\end{aligned}
$$

Estimates of the particle densities $\rho_{1}$ and $\rho_{2}$ (assumed to be height-independent) are required. Appropriate values of $\rho_{1}$ (mainly sulfate aerosol) and $\rho_{2}$ (desert and volcanic dust) can be found, e.g., in Ansmann et al. (2012). The final products of the LIRIC data analysis are summarized in the blue box in Fig. 1. To better compare the LIRIC results with the products of the POLIPHON method (Sect. 3.2), mass concentrations for spherical and non-spherical particles are computed in addition:

$$
\begin{aligned}
& M_{1}(z)=\rho_{1}\left[C_{\mathrm{f}, 1}(z)+C_{\mathrm{c}, 1}(z)\right], \\
& M_{2}(z)=\rho_{2}\left[C_{\mathrm{f}, 2}(z)+C_{\mathrm{c}, 2}(z)\right] .
\end{aligned}
$$

From the LIRIC backscatter and extinction coefficients after Eqs. (6) and (8), the lidar ratio profiles for the different wavelengths can be computed:

$S_{\text {aer, } \mathrm{e}}(\lambda, z)=\frac{\alpha_{\text {aer,e }}(\lambda, z)}{\beta_{\text {aer,e }}(\lambda, z)}$.

Several Ångström exponents (Ångström, 1961),

$\stackrel{\circ}{a}_{\mathrm{x}_{\mathrm{e}}}\left(\lambda_{1}, \lambda_{2}, z\right)=-\frac{\ln \left[x_{\mathrm{e}}\left(\lambda_{1}, z\right) / x_{\mathrm{e}}\left(\lambda_{2}, z\right)\right]}{\ln \left(\lambda_{1} / \lambda_{2}\right)}$,

where $\lambda_{1}<\lambda_{2}$ can be calculated from the profiles of the particle backscatter $\left(x_{\mathrm{e}}=\beta_{\mathrm{aer}, \mathrm{e}}\right)$ and extinction coefficients $\left(x_{\mathrm{e}}=\alpha_{\mathrm{aer}, \mathrm{e}}\right)$.

The photometer data in combination with the applied particle-scattering model (for spherical and spheroidal particles) permit the retrieval of column-mean backscatter coefficients as a function of the polarization state with respect to the incident laser light:

$$
\begin{aligned}
& b^{\perp}(\lambda)=b_{\mathrm{f}, 1}^{\perp}(\lambda)+b_{\mathrm{f}, 2}^{\perp}(\lambda)+b_{\mathrm{c}, 1}^{\perp}(\lambda)+b_{\mathrm{c}, 2}^{\perp}(\lambda), \\
& b^{\|}(\lambda)=b_{\mathrm{f}, 1}^{\|}(\lambda)+b_{\mathrm{f}, 2}^{\|}(\lambda)+b_{\mathrm{c}, 1}^{\|}(\lambda)+b_{\mathrm{c}, 2}^{\|}(\lambda) .
\end{aligned}
$$

For spherical particles the contributions to light depolarization are negligible in that $b_{\mathrm{f}, 1}^{\perp}(\lambda)=0$ and $b_{\mathrm{c}, 1}^{\perp}(\lambda)=0$. As mentioned, only non-spherical particles (desert dust, volcanic dust) cause significant depolarization. Instead of Eq. (6), we can write

$$
\begin{aligned}
\beta_{\mathrm{aer}, \mathrm{e}}^{\perp}(\lambda, z)= & C_{\mathrm{f}, 2}(z) b_{\mathrm{f}, 2}^{\perp}(\lambda)+C_{\mathrm{c}, 2}(z) b_{\mathrm{c}, 2}^{\perp}(\lambda), \\
\beta_{\mathrm{aer}, \mathrm{e}}^{\|}(\lambda, z)= & C_{\mathrm{f}, 1}(z) b_{\mathrm{f}, 1}^{\|}(\lambda)+C_{\mathrm{f}, 2}(z) b_{\mathrm{f}, 2}^{\|}(\lambda) \\
& +C_{\mathrm{c}, 1}(z) b_{\mathrm{c}, 1}^{\|}(\lambda)+C_{\mathrm{c}, 2}(z) b_{\mathrm{c}, 2}^{\|}(\lambda),
\end{aligned}
$$

so that we finally obtain the particle linear depolarization ratio:

$\delta_{\text {aer,e }}(\lambda)=\beta_{\text {aer, } \mathrm{e}}^{\perp}(\lambda) / \beta_{\text {aer, } \mathrm{e}}^{\|}(\lambda)$.

The photometer-derived profiles of the lidar ratio, Ångström exponents for backscatter and extinction, and depolarization ratio can be compared with the respective results directly determined from the Raman lidar observations (Ansmann et al., 1992; Mattis et al., 2004; Tesche et al., 2009a). This comparison is presented in Sect. 4.

With respect to the retrieval of mass concentration for dust particles, we can summarize that LIRIC uses photometerderived volume-specific backscatter and extinction coefficients for spherical as well as non-spherical particles for both fine and coarse modes. This AERONET information (column-integrated values) is then applied to determine height profiles of volume and mass concentration of spherical and non-spherical fine-mode particles and spherical and non-spherical coarse-mode particles by minimizing the differences between the modeled lidar profiles $L(\lambda, z)$ and the measured lidar profiles $L^{*}(\lambda, z)$. The important point is that LIRIC is based on the assumption that non-spherical particles can be described by a spheroidal-particle model. This may significantly affect the backscatter-coefficient, lidarratio, and depolarization-ratio retrievals (Gasteiger et al., 2011a; Müller et al., 2012), and thus the derived particle volume and mass concentrations. The implication of the model assumption on a spheroidal particle shape is discussed in Sect. 4 by comparing the LIRIC output with results obtained by means of the POLIPHON technique.

\subsection{Determination of particle mass concentrations by means of the POLIPHON technique}

An alternative approach for the retrieval of particle volume and mass concentration profiles is the single-wavelength POLIPHON technique (Ansmann et al., 2012). The method is based on measured profiles of the particle linear depolarization ratio and the lidar ratio at $532 \mathrm{~nm}$ and does not require the assumption of a specific particle shape. In this depolarization-ratio-based method it is assumed that the fine-mode-related backscatter and extinction coefficients are exclusively caused by non-depolarizing spherical particles (i.e., fine-mode fraction) and that the coarse mode consists of strongly light-depolarizing non-spherical particles only. Spherical coarse particles as well as non-spherical fine-mode particles are thus ignored in this method. If the particle depolarization ratio is $\geq 0.31$ in Saharan dust layers, the finemode particle fraction is set to $0 \%$. If the $532 \mathrm{~nm}$ depolarization ratio is $\leq 0.02$, the coarse-mode fraction is set to $0 \%$. For depolarization ratios from 0.02 to 0.31 we use the method described by Sugimoto et al. (2003) and Tesche et al. (2009a) to compute the height profiles of the backscatter coefficient $\beta_{\mathrm{aer}, 1}$ of spherical particles and of $\beta_{\mathrm{aer}, 2}$ of non-spherical particles at $\lambda=532 \mathrm{~nm}$. For volcanic dust, the data analysis is 
Table 1. Atmospheric and lidar input parameters and assumptions in the LIRIC and POLIPHON mass concentration retrievals as used in the paper. Overlap correction has only an impact on POLIPHON results for heights with $O\left(\lambda_{j}, z_{i}\right)<1$.

\begin{tabular}{lcc}
\hline Input parameter & LIRIC & POLIPHON \\
\hline Overlap correction & $\times$ & $(\times)$ \\
Minimum/maximum heights of data analysis range & $\times$ & \\
Rayleigh scattering, actual atmospheric profile & $\times$ & $\times$ \\
Reference backscatter coefficient & $\times$ & $\times$ \\
Refractive index, height-independent, same for fine and coarse mode & $\times$ & $\times$ \\
Column-mean sphericity, same for fine and coarse mode & $\times$ & $\times$ \\
Ratio of fine-mode spherical to non-spherical particles, height-independent & $\times$ & \\
Particle size distribution, height-independent & $\times$ & $\times$ \\
Spheroidal particle model (in $b_{m, s}(\lambda)$ computation) & $\times$ & \\
Volume-specific backscatter coefficient $b_{m, s}(\lambda)$, height-independent & $\times$ & \\
Spheroidal particle model (in $a_{m, s}(\lambda)$ computation) & $\times$ & $\times$ \\
Volume-specific extinction coefficient $a_{m, s}(\lambda)$, height-independent & $\times$ & $\times$ \\
Particle densities, fine mode, coarse mode $\rho_{1}, \rho_{2}$ & $\times$ & $\times$ \\
Particle lidar ratio, fine mode, coarse mode & & $\times$ \\
Fine-mode particles - spherical particles only & & $\times$ \\
Coarse-mode particles - non-spherical particles only & & $\times$ \\
\hline
\end{tabular}

the same except that the volcanic depolarization ratio is set to 0.34 (Ansmann et al., 2012).

As is the case for the LIRIC method, the POLIPHON technique makes use of photometer-derived volume-specific extinction coefficients $a_{\mathrm{f}}$ and $a_{\mathrm{c}}$ for fine-mode and coarsemode particles (Eq. 12). The values for $a_{\mathrm{f}}$ and $a_{\mathrm{c}}$ can directly be computed from volume concentrations $V_{\mathrm{f}}$ and $V_{\mathrm{c}}$ and AOTs $\tau_{\text {ext,f }}$ and $\tau_{\text {ext,c }}$ downloaded from the AERONET website. The parameters $a_{\mathrm{f}}$ and $a_{\mathrm{c}}$ are almost insensitive to particle shape effects (Dubovik et al., 2006), in contrast to scattering properties computed for a scattering angle of $180^{\circ}$ (as required in the LIRIC data analysis). The reason is that small-angle forward scattering mainly contributes to particle extinction and that the corresponding phase function segments for spheroidal and spherical particles are very similar (Dubovik et al., 2006).

The mass concentrations $M_{1}$ for spherical particles (fine mode) and $M_{2}$ for non-spherical particles (coarse mode) are estimated as follows:

$$
\begin{aligned}
M_{1}(z) & =\rho_{1}\left(\overline{V_{\mathrm{f}} / \tau_{\mathrm{ext}, \mathrm{f}}}\right) \beta_{\mathrm{aer}, 1}(z) S_{\mathrm{aer}, 1} \\
& =\rho_{1}\left(\overline{a_{\mathrm{f}}^{-1}}\right) \beta_{\mathrm{aer}, 1}(z) S_{\mathrm{aer}, 1}, \\
M_{2}(z) & =\rho_{2}\left(\overline{V_{\mathrm{c}} / \tau_{\mathrm{ext}, \mathrm{c}}}\right) \beta_{\mathrm{aer}, 2}(z) S_{\mathrm{aer}, 2} \\
& =\rho_{2}\left(\overline{a_{\mathrm{c}}^{-1}}\right) \beta_{\mathrm{aer}, 2}(z) S_{\mathrm{aer}, 2} .
\end{aligned}
$$

According to these equations, appropriate (actual) lidar ratios $S_{\text {aer, } 1}$ and $S_{\text {aer,2 }}$ are needed and obtained from the Raman lidar measurements or from combined photometer-lidar observations (Ansmann et al., 2011b, 2012). We use column lidar ratios in the mass concentration retrieval, disregarding that the Raman-lidar method provides lidar ratio profiles. Besides particle densities $\rho_{1}$ and $\rho_{2}$, temporal mean values of the volume-to-extinction conversion factors $\overline{V_{\mathrm{c}, \mathrm{f}} / \tau_{\mathrm{ext}, \mathrm{c}, \mathrm{f}}}$ are determined and inserted in Eqs. (26) and (27).

The main advantage of the POLIPHON method is that a particle shape model for irregularly shaped dust particles is not required. The particle depolarization ratio is used to separate spherical and non-spherical particle fractions. However, fine- and coarse-mode fractions as determined with LIRIC may not be well represented by these spherical and non-spherical particle fractions. A significant part of the non-spherical dust particles may belong to the fine mode, but are interpreted as coarse-mode particles when applying POLIPHON, i.e, when the non-spherical particle fraction is assumed to be identical to the coarse-mode fraction. This aspect is further discussed in the next section.

Table 1 provides finally an overview of the essential atmospheric and lidar system parameters required in the LIRIC and POLIPHON volume and particle mass concentration retrievals. From this comparison the contrast between the methods becomes very clear. Overlap corrections are critical in the LIRIC analysis because the lidar profiles as a whole are set into context with the column-integrated particle information from AERONET observations. Overlap effects affect the POLIPHON results only in the near range (incomplete overlap). Further important LIRIC assumptions are the spheroidal-particle model and the refractive-index characteristics because they sensitively influence the computation of the volume-specific backscatter coefficients (Gasteiger et al., 2011a) required in the LIRIC analysis scheme. As mentioned, the volume-specific extinction coefficients used in both the LIRIC and the POLPIHON methods are almost insensitive regarding particle shape effects (spheroidal versus spherical particle model), so the POLIPHON results are favorable to study the influence of the applied 
spheroidal-particle model on the LIRIC mass retrieval. The other assumptions and input parameters in Table 1 are less critical and introduce only minor uncertainties in the mass concentration retrieval. A critical aspect remains in the case of hygroscopic volcanic dust (Ansmann et al., 2012). As will be discussed below, at high relative humidities a part of the volcanic coarse dust may become spherical and may then be counted as fine-mode aerosol. Under these conditions, the volcanic dust concentrations will be underestimated.

\section{Results}

Two case studies are presented in the following. A strong Saharan dust outbreak reached central Europe at the end of May 2008. Anthropogenic and dust particles were almost perfectly separated with height. Urban haze occurred in the lowermost $700 \mathrm{~m}$ of the atmosphere, whereas desert dust was observed from 1 to $6 \mathrm{~km}$ height. Mixing was prohibited by a strong temperature inversion layer at the top of the haze layer. The fine-mode fraction (FMF, ratio of fine-mode AOT to total AOT) was $0.20-0.25$, and the spherical-particle volume fraction (sphericity) was estimated by the AERONET retrieval to be $1.7 \%$. Thus, practically all particles were irregularly shaped dust particles. Under these conditions, all simplifying LIRIC assumptions such as same refractive-index characteristics and same ratios of spherical to non-spherical particles in both particle modes are widely fulfilled so that optimum conditions are given to study the impact of the spheroidalparticle model on the retrieved profiles of dust optical and microphysical properties.

In contrast, the second case observed over Leipzig after the Eyjafjallajökull volcanic eruption in April 2010 deals with an aged volcanically disturbed air mass with vertically complex aerosol layering and mixing of spherical sulfate particles (fine mode) and non-spherical volcanic dust particles (fine-mode and coarse-mode particles). The volcanic particles may have been partly spherical because of water uptake at high relative humidity. In contrast to the Saharan dust case, the FMF was close to 0.8. Fine-mode particles dominated particle backscattering and extinction. The contribution of spherical particles to the particle volume concentration was on the order of $15 \%$ according to the AERONET retrievals. Very different refractive-index characteristics and very different ratios of spherical-to-non-spherical particles in fine mode and coarse mode can be expected. All basic assumptions of the LIRIC/AERONET approach, as listed in Table 1, were probably considerably violated. This second, complex aerosol case may especially show the limits of the synergy of column-integrated and profile observations. These two observational cases were already discussed in detail by Ansmann et al. (2012), so the LIRIC method can be applied to welldocumented and quality-checked lidar/photometer data sets.

\subsection{Saharan dust}

A long-lasting Saharan dust event was monitored with lidar and photometer from 25 to 31 May 2008. The particle optical thickness at $500 \mathrm{~nm}$ showed values around 0.7 from the early morning of 28 May 2008 to the early morning of 30 May 2008. Figure 2 shows lidar height-time displays of the $1064 \mathrm{~nm}$ range-corrected signal in the evening of 29 May 2008. Well-stratified dust layers up to $5.5 \mathrm{~km}$ were found. Persistent, long-lasting cirrus decks frequently occurred and disturbed the AERONET sun/sky photometer observations. A good opportunity to compare and combine lidar and photometer observations and to apply the LIRIC method was given in the evening of 29 May 2008. At around 17:30 UTC, the sky was cloud-free during several successive AERONET observations. Stable aerosol conditions (see discussion below) throughout the following night enabled the determination of the full set of Raman lidar results and ensured a perfect framework for a critical assessment of the LIRIC results.

Because of these very constant aerosol conditions we averaged all cloud-screened lidar profiles measured in the evening of 29 May 2008, 21:47 to 23:15 UTC, to minimize the impact of signal noise on the retrieval. The respective $1.5 \mathrm{~h}$ mean profiles of the three particle backscatter coefficients at 355, 532, and $1064 \mathrm{~nm}$ computed with Eq. (6) and the corresponding extinction profiles after Eq. (8) are presented in Fig. 3. In addition, the particle backscatter coefficient computed from the cross-polarized $532 \mathrm{~nm}$ backscatter signal is presented. This latter backscatter coefficient considers only backscattering by non-spherical particles according to Eq. (7). Figure 3 also shows the corresponding profiles of the volume concentrations for fine-mode and coarse-mode particles as retrieved with LIRIC. As mentioned, the vertically integrated fine-mode and coarse-mode volume concentrations must match the respective column values retrieved from AERONET observations.

As outlined above, the lidar was well aligned on this day and the overlap function well characterized. The incomplete overlap between laser beam and RFOV could be corrected with sufficient accuracy down to $z_{N_{0}}=150 \mathrm{~m}$ height. The reference height $z_{N}$ was set to $9 \mathrm{~km}$ height. The $500 \mathrm{~nm}$ AOT measured with the AERONET photometer was 0.73 at 17:30 UTC and 0.70 the next morning.

The particle backscatter coefficients show a weak reversed spectral order (negative Ångström exponent) in the dust layer between $500 \mathrm{~m}$ and $5.5 \mathrm{~km}$ height and almost no wavelength dependence in terms of the extinction coefficient. In the pollution layer below $600 \mathrm{~m}$ height, a strong decrease of the backscatter and extinction coefficients with wavelength is found according to Ångström values of around 1.5. The volume concentration profiles show a dominant coarse particle mode in the height range of $600 \mathrm{~m}$ to $6 \mathrm{~km}$. The fine-mode particles predominantly occur in the boundary layer below $600 \mathrm{~m}$ and another weak accumulation of fine particles is 


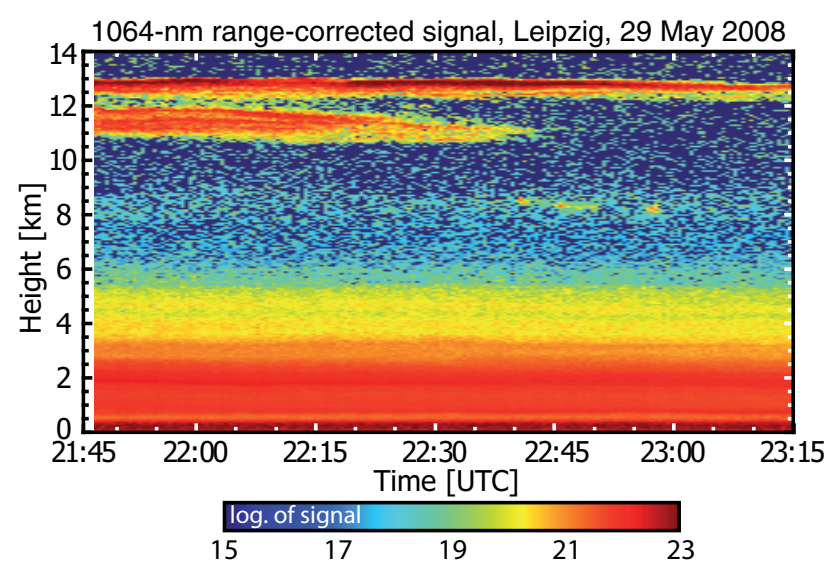

Fig. 2. Range-corrected signal at $1064 \mathrm{~nm}$ measured on 29 May 2008, 21:47-23:15 UTC (signal counts in logarithmic scale). The vertical resolution of the lidar measurement is $60 \mathrm{~m}$; the temporal resolution is $30 \mathrm{~s}$. The $500 \mathrm{~nm}$ AOT was $0.7-0.75$ up to $6 \mathrm{~km}$ height in the evening of 29 May.

found around $2 \mathrm{~km}$. The reversed backscatter spectrum in the dust layer may be caused by the use of the spheroidal-particle model in the LIRIC/AERONET retrieval as further discussed below.

As mentioned, the error bars in Fig. 3 only account for uncertainties in the input parameters of the LIRIC procedure, and not for uncertainties in the basic lidar signal profiles. We estimated a potential impact of the overlap correction by using three different but reasonable overlap profiles, and found that the results shown in Fig. 3 varied by up to $25 \%$ in the lowermost $1500 \mathrm{~m}$ and on the order of $5 \%$ in the aerosol layers up to $3500 \mathrm{~m}$. Variations of the reference height and minimum measurement height in the LIRIC data analysis by $\pm 1 \mathrm{~km}$ lead to variations in the backscatter and extinction coefficients by up to $50 \%$ in the lowermost $1500 \mathrm{~m}$ and around $15 \%$ in the aerosol layers. However, many of these resulting LIRIC profiles then show, e.g., a constant but unrealistic offset above the main aerosol layers (around the reference height) and can thus be sorted out by visual inspection. Nevertheless, a careful study of the impact of the overlap correction and setting of the minimum and reference heights is an important part of the lidar data analysis and an important prerequisite for high-quality LIRIC products.

Figure 4 shows a comparison of the LIRIC backscatter coefficients at $532 \mathrm{~nm}$ with respective backscatter profiles directly retrieved from the Raman lidar observations (total backscatter coefficient, for simplicity denoted as POLIPHON curves) and derived by using the separation method of Tesche et al. (2009a) for the spherical and non-spherical particle fractions. As can be seen, the total backscatter coefficients agree well. The respective $532 \mathrm{~nm}$ extinction coefficient in Fig. 3 is however overestimated by $10-20 \%$ in the dust layer when compared to the direct Raman lidar observation (not shown), and thus also the dust

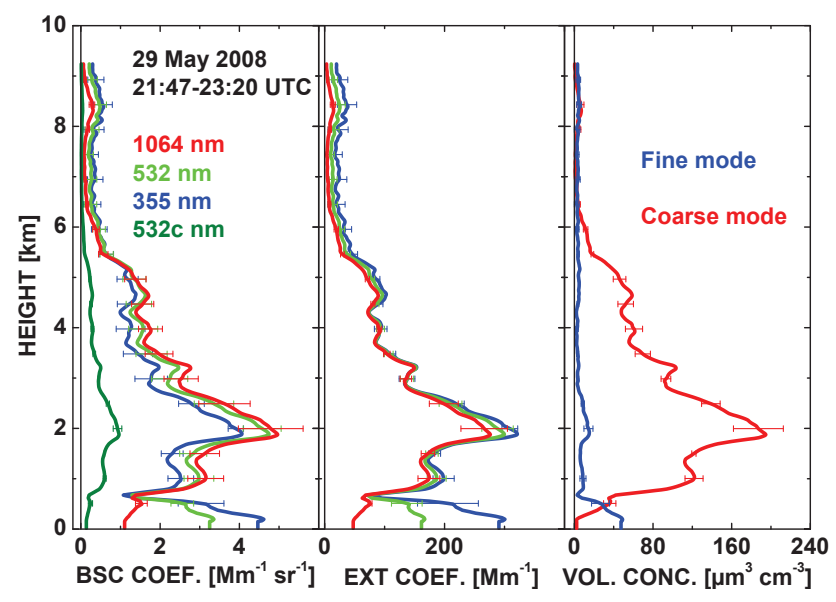

Fig. 3. Mean particle optical parameters (left: backscatter coefficient, center: extinction coefficient) for three laser wavelengths, backscatter coefficient for the cross-polarized $532 \mathrm{~nm}$ lidar channel (left, $532 \mathrm{c} \mathrm{nm}$, dark green), and particle volume concentration profiles (right) for fine-mode and coarse-mode fractions retrieved with the LIRIC method based on the lidar observations on 29 May 2008 shown in Fig. 2. The vertical resolution is $15 \mathrm{~m}$. The reference height is set to $z_{N}=9 \mathrm{~km}$ and the minimum measurement height is $z_{N_{0}}=150 \mathrm{~m}$. The error bars show the uncertainties (standard deviation) of the LIRIC results (see discussion in Sect. 3.1).

extinction-to-backscatter ratio is overestimated (more details are given below).

In the central and left parts of Fig. 4, the LIRIC backscatter coefficients for non-spherical and spherical particles are shown and compared with the respective POLIPHON result. In addition, the LIRIC backscatter profiles for the fine mode and coarse mode are given. The sphericity as provided by the AERONET retrieval plays an important role in the LIRIC data analysis. The spherical particle volume fraction is $1.7 \%$ after AERONET and finally $0.1 \%$ in the LIRIC data set. According to the POLIPHON volume concentrations the sphericity is $8.5 \%$. As a consequence, the LIRIC nonspherical particle backscatter coefficients are slightly larger than the respective POLIPHON values in the lofted Saharan dust layer and considerably larger in the haze layer below $700 \mathrm{~m}$ height. By comparing the LIRIC coarse-mode backscatter profile with the one for non-spherical particles, we obtain an impression as to how much of the backscatter is caused by non-spherical fine-mode particles. Because of the low AERONET sphericity value the backscatter coefficient for spherical particles is almost zero at all heights. In contrast, the respective POLIPHON curve shows that spherical particles considerably contributed to backscattering in the haze layer. This fine-mode backscatter in the lowermost $700 \mathrm{~m}$ is attributed to non-spherical particles after LIRIC (see center plot in Fig. 4).

Figure 5 shows the LIRIC mass concentration profiles separately for non-spherical and for spherical particles (Eqs. 17-18) and for fine mode and coarse modes 


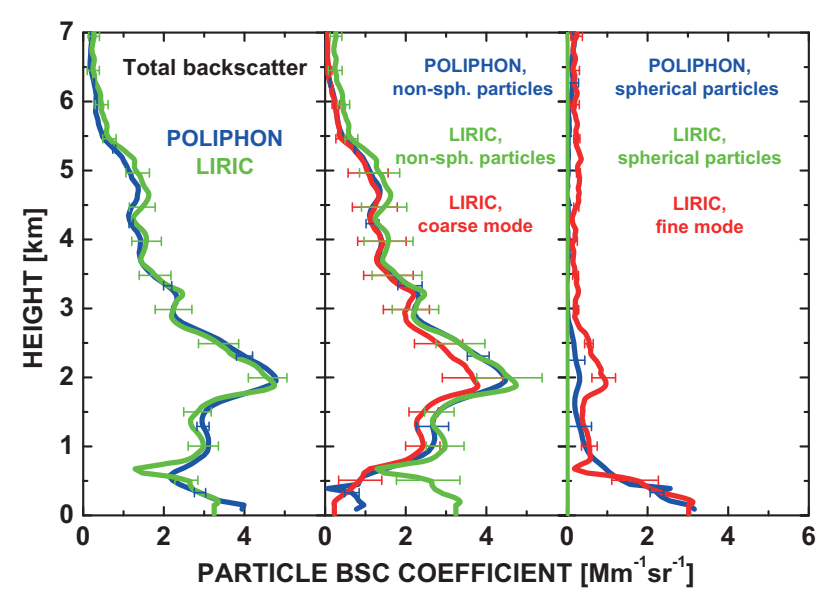

Fig. 4. Comparison of LIRIC- and POLIPHON-derived particle backscatter coefficients observed on 29 May 2008. The blue POLIPHON curves are taken from Fig. 2 of Ansmann et al. (2012). The error bars indicate the uncertainties of the retrieval products as discussed in Sect. 3.1 (LIRIC) and in Ansmann et al. (2011a, 2012) (POLIPHON).

(Eqs. 15-16). The LIRIC profiles are compared with respective POLIPHON profiles for non-spherical and spherical particles (Eqs. 26-27). Particle densities of $\rho_{2}=2.6 \mathrm{~g} \mathrm{~cm}^{-3}$ and $\rho_{1}=1.6 \mathrm{~g} \mathrm{~cm}^{-3}$ are assumed for non-spherical and spherical particles, respectively. As can be seen, good agreement of the LIRIC and POLIPHON results for non-spherical and coarsemode particles is found. The slightly larger LIRIC values are again caused by the low LIRIC sphericity value of $0.1 \%$, which leads to an overestimation of the non-spherical particle volume fraction (compared to the POLIPHON volume concentrations). This good agreement suggests that the nonspherical (light depolarizing) particle fraction well represents the coarse mode in the particle volume and mass retrievals in this case of a strong Saharan dust outbreak.

As a further consequence of the low AERONET sphericity value, the mass concentration for spherical particles is almost zero (not visible in the right plot of Fig. 5), whereas the POLIPHON approach suggests a considerable mass concentration of spherical, roughly as large as the LIRIC fine-mode mass concentration. The POLIPHON results are more realistic. It is at least unrealistic to assume that the mass concentration of non-depolarizing urban haze over the central European city of Leipzig was negligible in the lowermost $700 \mathrm{~m}$ of the atmosphere on this specific day with a huge Saharan dust outbreak.

The sphericity parameter is of central importance in the separation of dust (non-spherical particles) and non-dust volume and mass concentrations with the LIRIC method. The spheroidal-particle model can thus be regarded as one uncertainty source leading to too low sphericity values. However, it is also possible that the POLIPHON pure dust depolarization ratio of $31 \%$ used in the separation of dust and

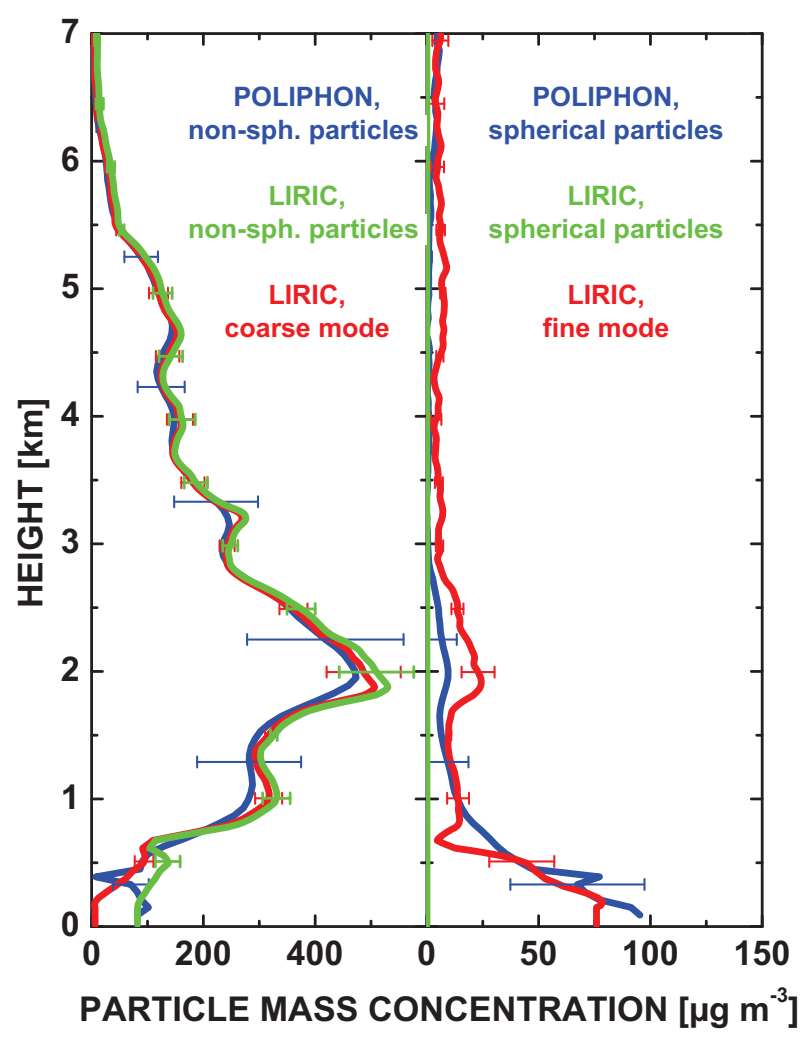

Fig. 5. Comparison of LIRIC- and POLIPHON-derived particle mass concentrations, observed on 29 May 2008. The blue POLIPHON curves are taken from Fig. 2 of Ansmann et al. (2012). Error bars indicate the uncertainties (one standard deviation).

non-dust aerosol components is too high. Lower threshold values (below $30 \%$ ) lead to a decrease of the POLIPHONderived sphericity, i.e., to an increase of the contribution of non-spherical particles to the observed optical effects. On the other hand, as will be discussed below, the use of the spheroidal-particle model causes too low dust depolarization ratios when compared with directly measured depolarization ratios for desert dust (Müller et al., 2010, 2012; Gasteiger et al., 2011a) and thus a too large sphericity value.

The applicability of the spheroidal-particle model is further illuminated in Figs. 6 and 7. LIRIC results for the intensive particle parameters such as particle lidar ratio, depolarization ratio, and Ångström exponents are shown and compared with direct Raman lidar observations. The $532 \mathrm{~nm}$ lidar ratios (LIRIC, Eq. 19) are determined by dividing the $532 \mathrm{~nm}$ extinction coefficients by the $532 \mathrm{~nm}$ backscatter values in Fig. 3. The Ångström exponents are computed from the 355 , 532, and $1064 \mathrm{~nm}$ backscatter and 355 and $532 \mathrm{~nm}$ extinction coefficients in Fig. 3 by means of Eq. (20). In the case of the LIRIC particle depolarization ratios, the backscatter coefficients computed from the cross-polarized and total signals shown in Fig. 3 are used according to Eq. (25). 


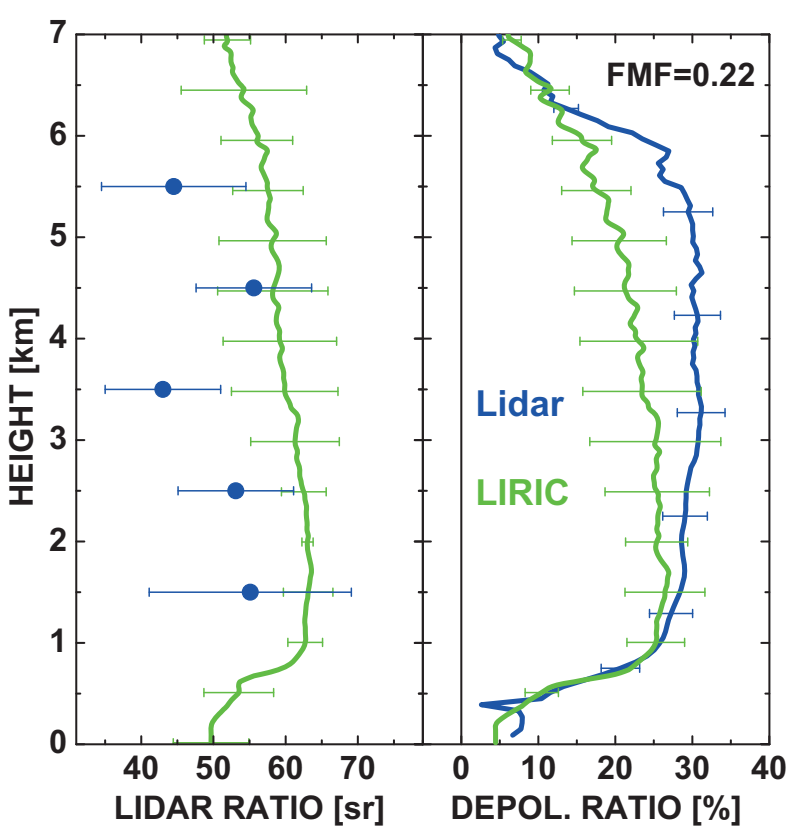

Fig. 6. Particle lidar ratio at $532 \mathrm{~nm}$ (blue circles) and particle depolarization ratio at $532 \mathrm{~nm}$ (blue curve) observed on 29 May 2008 with Raman lidar and derived by using the LIRIC profiles in Fig. 3 (green curves). Raman lidar signals are smoothed with window lengths of about $1000 \mathrm{~m}$ in the case of the lidar ratio (blue symbols). Errors bars indicate the uncertainties (one standard deviation). The depolarization ratio profile is given with $60 \mathrm{~m}$ resolution.

As can be seen, the particle lidar ratio in the dust layer and the spectral slope (or Angström exponent) of the dust lidar ratio are systematically overestimated by the LIRIC/AERONET approach, and correspondingly the backscatter-related Ångström exponent is clearly underestimated. In addition, the values of the particle depolarization ratio in the lofted dust layer are systematically lower than the directly measured ones. These discrepancies are in full agreement with the findings from the SAMUM observations in southern Morocco (Gasteiger et al., 2011a; Müller et al., 2010, 2012). These deviations of LIRIC profiles from the measured values (Raman lidar) clearly point to the spheroidal-particle model as main error source. Directly observed lidar ratios for 355 and $532 \mathrm{~nm}$ are around 50-55 sr in Fig. 6. These values are typical for the western Saharan dust (Tesche et al., 2009b; Schuster et al., 2012). The LIRIC backscatter and extinction profiles lead to dust lidar ratios of $78-80 \mathrm{sr}(355 \mathrm{~nm})$ and $60-62 \mathrm{sr}(532 \mathrm{~nm})$ in the height range of 1500 to $3000 \mathrm{~m}$ (center part of the dust layer).

However, the lidar ratio (or better the particle backscatter coefficient) depends in a complicated way on the chemical composition (refractive-index characteristics), size distribution, particle shape, and aspect ratio (particle lengthto-width ratio) distributions. It remains an open question to what extent the spheroidal-particle model is responsible for

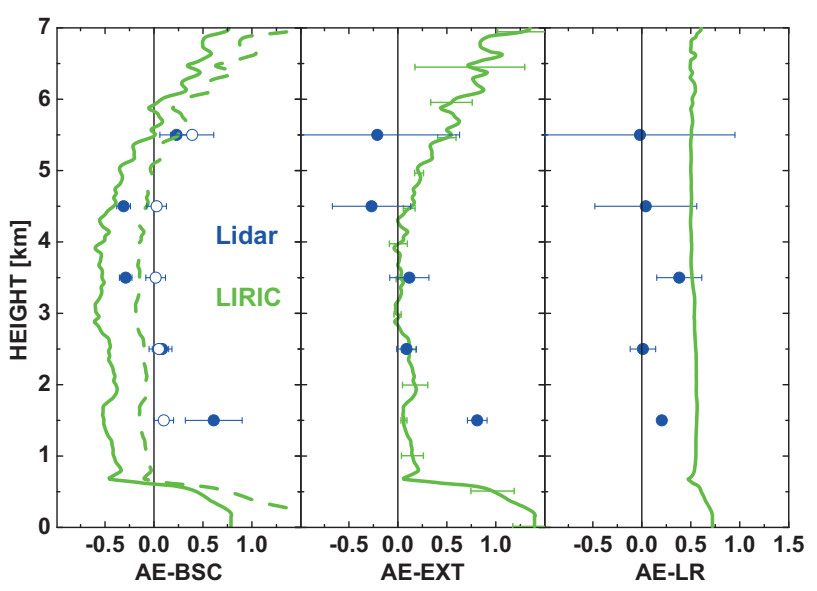

Fig. 7. Backscatter-related Ångström exponent (AE-BSC), extinction-related Ångström exponent (AE-EXT), and lidar-ratiorelated Ångström exponent (AE-LR) observed on 29 May 2008 with Raman lidar (blue circles) and derived by using the LIRIC profiles in Fig. 3 (green curves). Solid green curve and closed blue symbols show the Ångström exponents for the $355-532 \mathrm{~nm}$ wavelength range; dashed green curve and open blue symbols for the 532-1064 nm spectral range. As outlined by Ansmann et al. (2002), AE-EXT $=\mathrm{AE}-\mathrm{BSC}+\mathrm{AE}-\mathrm{LR}$. Raman lidar signals are smoothed with window lengths of about $1000 \mathrm{~m}$ in the case of extinction coefficients and the lidar ratio, and $60 \mathrm{~m}$ in the case of the backscatter coefficients. Errors bars indicate the uncertainties (one standard deviation). LIRIC error bars are given for AE-EXT only.

the observed systematic bias in the Ångström exponents and lidar ratios. Furthermore, the a priori AERONET input data are provided as column values, ignoring the observed aerosol layering with a lofted dust aerosol layer above the central European haze layer. As a last point, in LIRIC the same refractive index is used for both fine-mode and coarse-mode particles, disregarding the fact that fine-mode sulfate particles and coarse-mode desert dust particles show different scattering and absorption properties including respective wavelength dependence.

The depolarization ratio strongly depends on particle shape. During SAMUM, dust depolarization ratios were around $0.23-0.25(355 \mathrm{~nm})$ and $0.30-0.35(532 \mathrm{~nm})$. Müller et al. $(2010,2012)$ found $20 \%(355 \mathrm{~nm})$ to $30 \%(532 \mathrm{~nm})$ lower particle depolarization ratios from the SAMUM AERONET computations assuming spheroidal particles with smooth surfaces. Very similar deviations are shown in Fig. 7. Gasteiger et al. (2011a) studied the depolarization ratios for spheroids with smooth surfaces and spheroids with deformations (rough surfaces) based on modeling. The depolarization ratio increases by $20-30 \%$ when spheroids with rough surfaces are assumed. Spheroids with surface deformations also better reproduce the measured lidar ratios (reducing the overestimation) than spheroidal particles with smooth surfaces. It remains to be mentioned that fine-mode spheroidal particles 


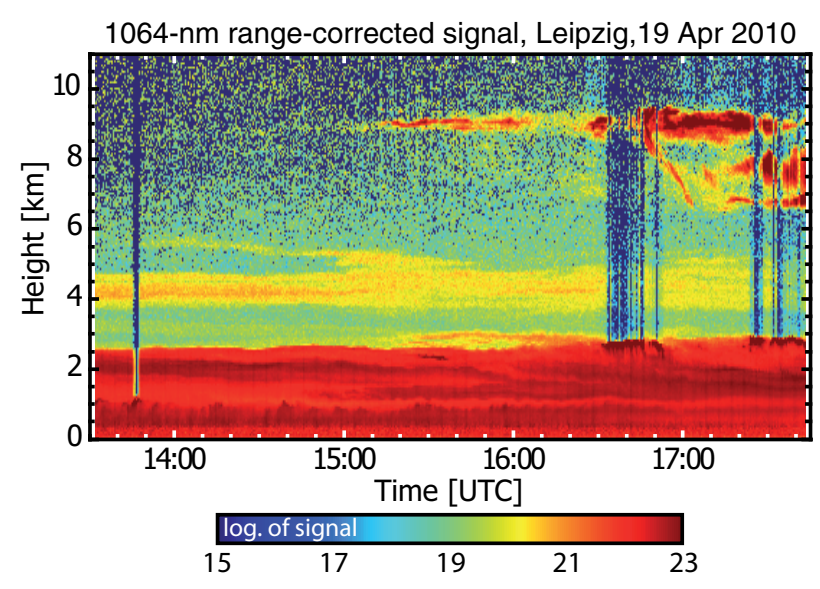

Fig. 8. Range-corrected signal at $1064 \mathrm{~nm}$ on 19 April 2010, 13:3217:43 UTC. The vertical resolution is $60 \mathrm{~m}$; the temporal resolution is $30 \mathrm{~s}$. The $500 \mathrm{~nm}$ AOT was 0.7 up to $6 \mathrm{~km}$ height in the afternoon of 19 April.

produce a particle depolarization ratio about $5-6 \%$, as can be seen in Fig. 6 (right panel), at heights below $500 \mathrm{~m}$ (LIRIC profiles).

\subsection{Volcanic ash}

In April 2010, an aged volcanic aerosol layer consisting of a mixture of volcanic dust, volcanic sulfate particles, and anthropogenic haze occurred over central Europe. These aerosol conditions provided a unique opportunity to apply the LIRIC approach to another type of irregularly shaped aerosol particles. In contrast to desert dust, volcanic dust is hygroscopic (Lathem et al., 2011), so changes in the shape characteristics by water uptake cannot be excluded when relative humidity is high (i.e., $>70 \%$ ) (Ansmann et al., 2012). As a consequence, spherical particles may occur not only in the fine-mode but also in the coarse-mode fraction, and thus may complicate the interpretation of POLIPHON results and the comparison with LIRIC results. The contribution of spherical particles to the particle volume concentration was about $15 \%$ according to the AERONET data analysis.

The volcanic layers observed on 19 April 2010 originated from the Eyjafjallajökull volcanic eruptions in Iceland on 14 April 2010 (Ansmann et al., 2011a; Schumann et al., 2011). Figure 8 shows the situation in the afternoon of 19 April 2010. The $500 \mathrm{~nm}$ AOT was about 0.7, and the FMF about 0.8 . The well-mixed boundary layer reached up to $1000-1400 \mathrm{~m}$ height on that day. Above the boundary layer another layer of $1500 \mathrm{~m}$ thickness occurred mainly consisting of volcanic dust. Between 3.8 and $5.5 \mathrm{~km}$ height a further dust layer was detected consisting of fine-mode and coarsemode particles. At heights around $9 \mathrm{~km}$ a cirrus layer developed after 15:00 UTC. Photometer measurements at cloudfree conditions became almost impossible after 16:00 UTC.

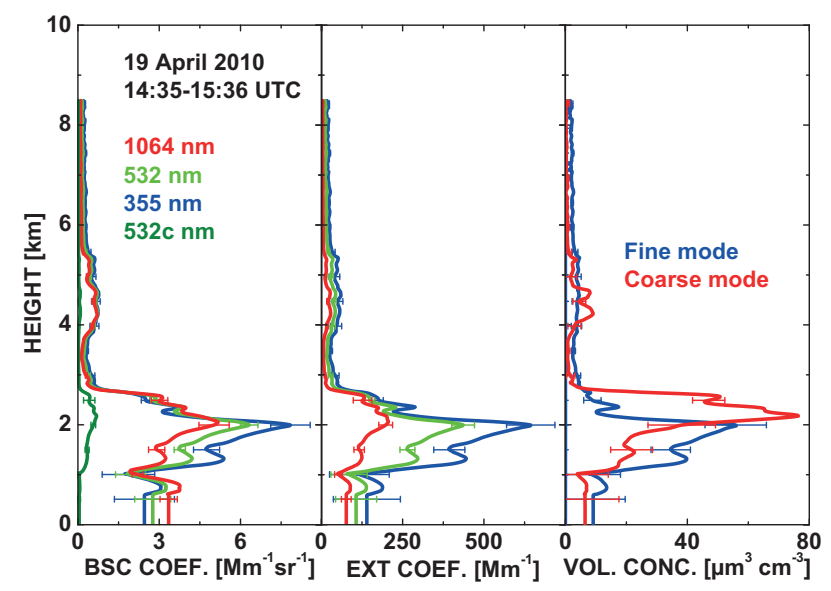

Fig. 9. Same as Fig. 3 except for a volcanic dust observation on 19 April 2010, 14:35-15:36 UTC with retrieval reference height of $z_{N}=8.25 \mathrm{~km}$ and minimum measurement height of $z_{N_{0}}=600 \mathrm{~m}$.

Figure 9 shows the LIRIC products in terms of profiles of particle backscatter coefficient, extinction coefficient, and particle volume concentration for the fine-mode and coarse-mode fraction. LIRIC calculations were performed with cloud-screened lidar signal profiles for the time period from 14:35 to 15:36 UTC on 19 April 2010. The considered photometric measurements were taken at 14:49 UTC. Lidar signals were only used up to $8.25 \mathrm{~km}$ height (reference point) because of cirrus cloud evolution above this height. The minimum measurement height $z_{N_{0}}$ was set to $600 \mathrm{~m}$.

According to the volume concentration profiles in Fig. 9, a strongly varying mixture of fine-mode and coarse-mode particles was observed throughout the troposphere. Cumulus cloud development at around 13:45 UTC at $1 \mathrm{~km}$ height (see Fig. 8) indicates high relative humidity of $>80 \%$ close to the top of the boundary layer. Thus particle water-uptake effects must be taken into account in the data interpretation. The relative humidity was about $60 \%$ in the lofted layer from 1.5 to $2.8 \mathrm{~km}$ and less than $30 \%$ in the layer above $3.5 \mathrm{~km}$ height around 15:00 UTC (Ansmann et al., 2012). After 16:00 UTC, the relative humidity increased and was high up to $2.8 \mathrm{~km}$ height.

The backscatter and extinction coefficients retrieved with LIRIC show a pronounced, fine-mode-dominated wavelength dependence from 1 to $2.2 \mathrm{~km}$. Above $2 \mathrm{~km}$ the backscatter coefficients are nearly the same for all wavelengths, caused by the dominating coarse-mode particle fraction. The reversed backscatter wavelength spectrum at low heights $(0-1 \mathrm{~km})$ is related to the presence of irregularly shaped volcanic particles and the use of the spheroidal model to compute the extinction-to-backscatter ratios.

In a similar way as for the Saharan dust case, Figs. 10 to 13 show the LIRIC results for this volcanic event in comparison with POLIPHON profiles and Raman lidar observations of optical properties of the particles. These comparisons 


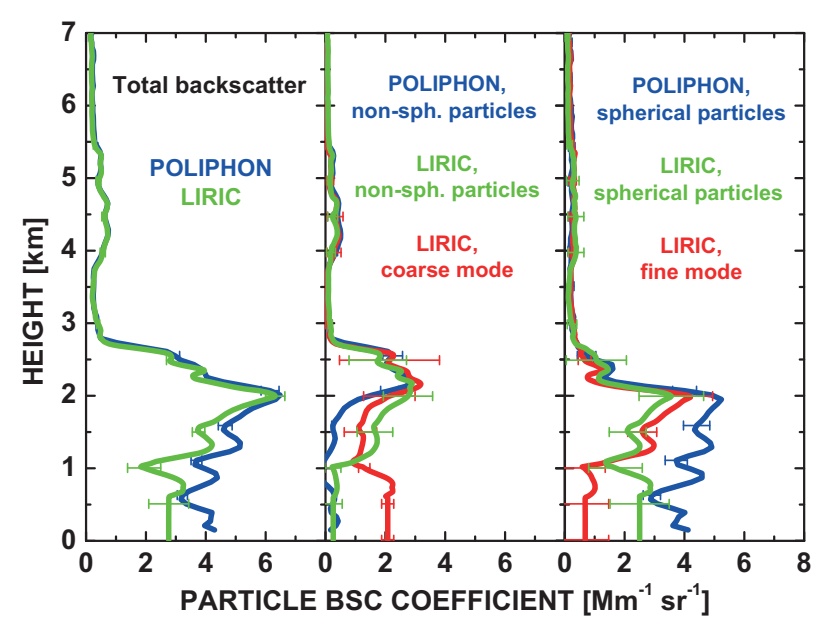

Fig. 10. Same as Fig. 4 except for a volcanic dust observation on 19 April 2010. The POLIPHON curves are taken from Fig. 4 of Ansmann et al. (2012).

are much more difficult to interpret than it was the case for the Saharan dust outbreak. Coarse-mode volcanic dust particles were mixed with fine-mode sulfate particles. The degree of mixing changed with height, and strong gradients in the aerosol concentrations were observed. In view of these complex, height-variable aerosol conditions, a detailed error analysis (identification of specific uncertainty sources) is not possible. The column-related, height-independent volumespecific backscatter and extinction coefficients as derived from the AERONET observations for the different aerosol types introduce uncertainties in the LIRIC as well as the POLIPHON results.

As can be seen in Fig. 10, the profiles of the particle backscatter coefficients do not agree well with the ones directly determined from the Raman lidar observations at heights below $2 \mathrm{~km}$. Part of the systematic deviations in the lowermost $2 \mathrm{~km}$ may be caused by an erroneous correction of the overlap effect. The LIRIC backscatter coefficients are based on the elastic backscatter signals and are thus very sensitive to uncertainties in the overlap correction. The Raman lidar backscatter values in Fig. 10 are calculated from signal ratios (ratio of elastic backscatter signal to nitrogen Raman signal) so that the overlap effect (affecting both signals in almost the same manner) widely cancels out. As mentioned, the uncertainty in the overlap correction can cause uncertainties of about $25 \%$ in the backscatter coefficients for heights below $1.5 \mathrm{~km}$ height that then decrease quickly with height.

The LIRIC and POLIPHON total backscatter coefficients in the layers from 2 to $3 \mathrm{~km}$ and 4 to $5.5 \mathrm{~km}$ height agree well. The spherical particle volume fraction was about $15 \%$ after AERONET, finally $16.8 \%$ in the LIRIC data set, and $55 \%$ after POLIPHON. This means that the non-spherical particle fraction is much higher in the case of the LIRIC profiles compared to POLIPHON. As a consequence, the LIRIC

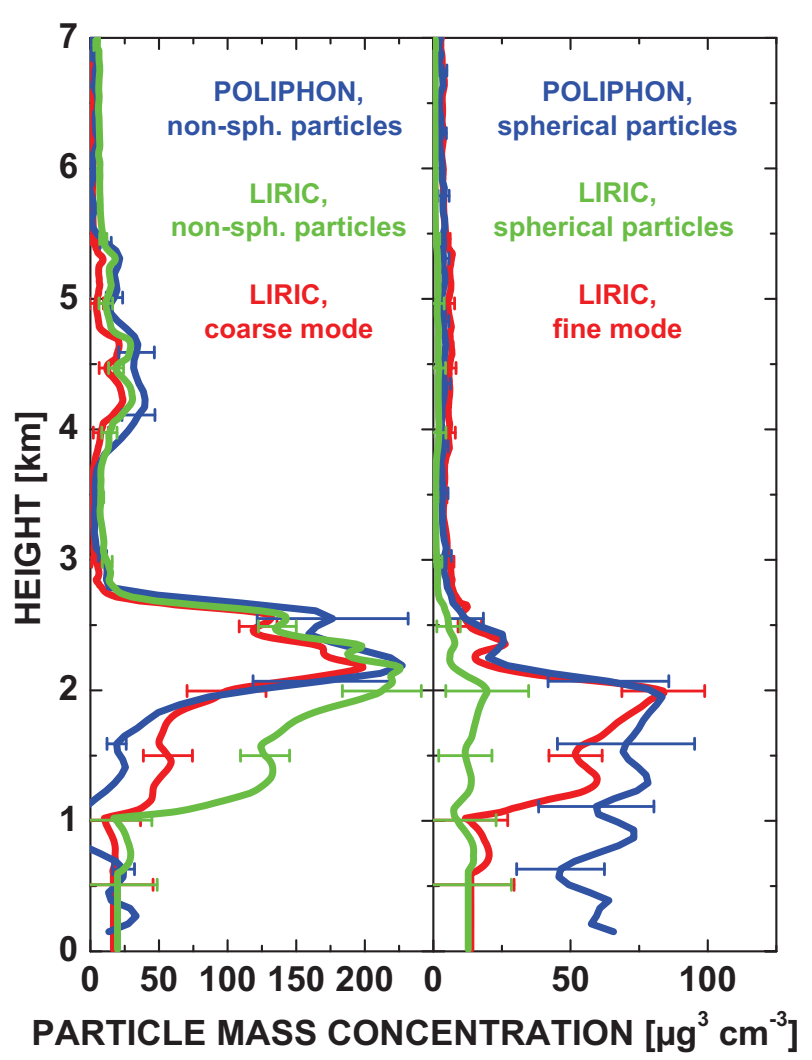

Fig. 11. Same as Fig. 5 except for a volcanic dust observation on 19 April 2010. The POLIPHON curves are taken from Fig. 4 of Ansmann et al. (2012).

non-spherical particle backscatter coefficients are, on average, larger in Fig. 10 (central panel). A pronounced overestimation occurs in the layer from 1 to $2 \mathrm{~km}$ height. Consequently a strong underestimation is found in the case of the backscatter profile for spherical particles.

The comparison of the LIRIC coarse-mode backscatter profiles with the LIRIC non-spherical particle backscatter profiles indicates that the coarse-mode values are dominated by spherical particles in the lowermost $1 \mathrm{~km}$ of the atmosphere. Also, the fine-mode particles are obviously mostly spherical.

As a direct consequence of the strong difference in the sphericity values, considerable deviations between the LIRIC and the POLIPHON mass concentrations are visible in Fig. 11. If we eliminate the particle density impact $\left(\rho_{1}=\right.$ $1.6 \mathrm{~g} \mathrm{~cm}^{-3}$ for spherical particles and $\rho_{2}=2.6 \mathrm{~g} \mathrm{~cm}^{-3}$ for non-spherical particles) and show the volume concentration profiles (the basic LIRIC product), the findings remain almost the same. Thus, a more basic comparison in terms of volume concentrations is not needed here. As in the case of the backscatter coefficients, the coarse-mode particle mass concentrations (LIRIC, POLIPHPON) agree reasonably well above $2 \mathrm{~km}$ height, and strongly deviate in the layer from 


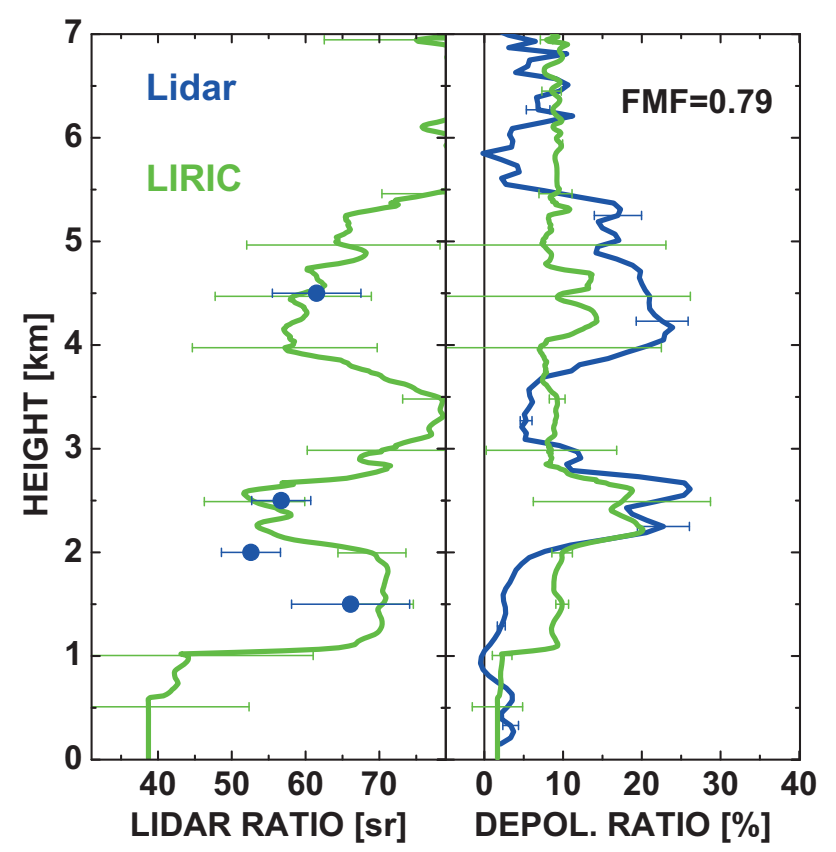

Fig. 12. Same as Fig. 6 except for a volcanic dust observation on 19 April 2010, 13:30-15:30 UTC. Lidar signals are smoothed with $660 \mathrm{~m}$ vertical window length in the case of the Raman lidar solutions for the lidar ratio.

1 to $2 \mathrm{~km}$ height. The POLIPHON spherical particle mass concentrations at heights below $2 \mathrm{~km}$ are almost a factor of 4 larger than the LIRIC/AERONET values. The comparison of LIRIC coarse-mode and fine-mode mass profiles with the LIRIC profiles for non-spherical and spherical particles show that most of the non-spherical volcanic dust particles in the $1-2 \mathrm{~km}$ layer belong to the fine mode.

However, it must be kept in consideration in these POLIPHON/LIRIC comparisons that also the POLIPHON profiles are based on AERONET retrieval products (see Sect. 3.2) and are thus uncertain. Further assumptions and related uncertainties affect the accuracy (Ansmann et al., 2011a, 2012). The respective relative errors are in the range of $20-50 \%$, as indicated in Fig. 11. Furthermore, if a part of the volcanic particles changes from non-spherical to spherical shape at high relative humidity, the fine-mode mass concentration will be overestimated and the coarse-mode mass concentration underestimated.

Figures 12 and 13 show the comparison of the LIRIC results with the direct Raman lidar observations of the $532 \mathrm{~nm}$ lidar ratio, particle linear depolarization ratio, and several Ångström exponents. Considering the complicated aerosol situation with all the assumption uncertainties, the agreement of the different lidar ratio profiles is reasonable. The differences between the depolarization ratios result from the assumed sphericity of $16.8 \%$ (LIRIC) and derived sphericity of $55 \%$ (POLIPHON).

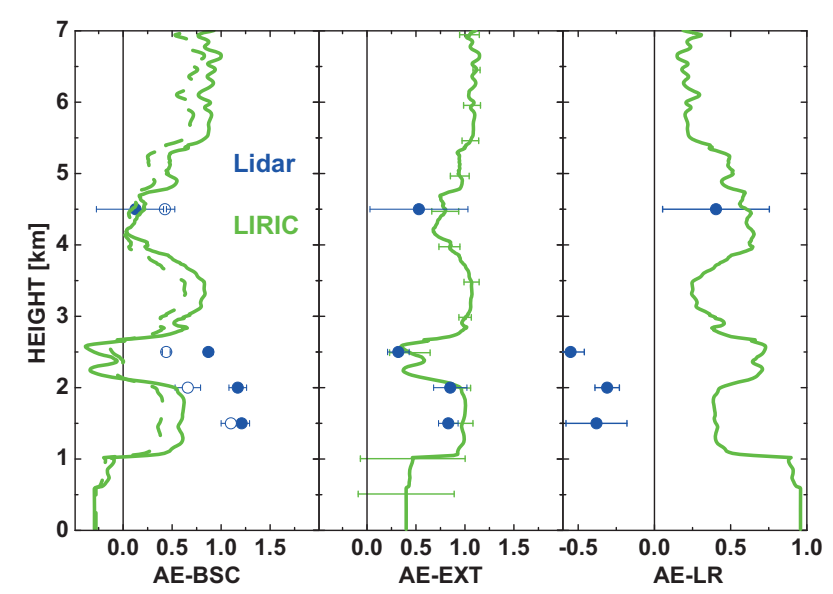

Fig. 13. Same as Fig. 7 except for a volcanic dust observation on 19 April 2010. LIRIC profiles are derived from Fig. 9 (green curves). Raman lidar observations (blue circles) were performed from 13:30 to 15:30 UTC. Raman lidar signals are smoothed with window lengths of $660 \mathrm{~m}$ in the case of extinction coefficients and the lidar ratio.

The profiles of the Ångström exponents show partly strong deviations, especially in the case of the backscatter and lidar ratio values. A negative Ångström exponent for the lidar ratio, as observed with our Raman lidar, indicates an aged aerosol with a high amount of comparably large fine-mode particles (Müller et al., 2005; Nicolae et al., 2013). In such aerosol situations, the lidar ratio at $355 \mathrm{~nm}$ is significantly lower than the one at $532 \mathrm{~nm}$. LIRIC retrieves the opposite, a positive lidar-ratio-related Ångström exponent. Such a complicated aerosol case can obviously not be adequately handled by the LIRIC/AERONET data analysis scheme. The found disagreement in the intensive aerosol parameters corroborate our statement at the beginning of this section that many basic assumptions of LIRIC are not valid under these conditions.

\section{Conclusions}

The LIRIC method was applied to two very different aerosol scenarios to evaluate the potential and limits of the retrieval of optical and microphysical properties of irregularly shaped dust particles. This new technique makes use of a combination of aerosol profile measurements with three-wavelength elastic-backscatter lidar and column-integrated aerosol observations with spectrally resolving sun/sky photometers.

Before the LIRIC analysis scheme can be applied, a careful overlap correction of the lidar signals is necessary, a reasonable assumption regarding the aerosol optical properties in the lowermost troposphere has to be made, and a careful Rayleigh backscattering and extinction computation based on actual temperature and pressure profiles has to be performed. It is essential that the entire troposphere is 
well covered by proper aerosol lidar observations. In general, the use of lidars with at least two receiver units for nearrange and far-range observations is desirable to guarantee high-quality LIRIC products. Conversely, small lidars such as ceilometers may cover the lowest heights only, but may not be able to provide proper aerosol observations in lofted layers in the middle and upper troposphere. LIRIC applications are also difficult in these cases.

A priori AERONET retrieval products are required and can introduce significant uncertainties. The representation of irregularly shaped desert and volcanic dust particles by a size distribution of spheroidal particles is one important error source. The use of the same refractive-index characteristics for the fine and coarse mode is another important source of uncertainty. In the case of complex aerosol layering and mixing, the use of column-integrated (height-independent) AERONET parameters causes further uncertainties in the LIRIC products.

The LIRIC aerosol profiles were compared with results obtained with the single-wavelength polarization lidar method POLIPHON and direct Raman lidar observation of basic particle backscatter and extinction properties. Two cases were contrasted. A comparably simple, well-stratified Saharan dust case in May 2008 with almost no spherical particles in the tropospheric column was discussed first, and then a rather complex case of layering of coarse volcanic dust and finemode anthropogenic and volcanic sulfate aerosol in April 2010 was presented. A detailed discussion of the findings and the potential impact of the assumed spheroidal-particle model was possible for the Saharan dust outbreak, but not for the complex volcanic aerosol event.

In the Saharan dust case, typical uncertainty features (biases) for desert dust introduced by the use of the spheroidalparticle model were found in the LIRIC-derived optical properties, similar to the ones observed during the SAMUM campaign in the AERONET data. However, coarse-mode particle mass concentrations obtained with LIRIC showed acceptable agreement with an alternative retrieval method that is not based on spheroidal-particle assumptions. The reason is most probably that specific extinction coefficients are the basis in the mass concentration retrieval and extinction values are not very shape-sensitive.

In the complex volcanic aerosol case, also considerable deviations of the LIRIC-derived optical properties from the direct Raman lidar observations were found. Coarse-mode particle mass values also deviated from the ones obtained with the alternative POLIPHON technique. A detailed error analysis was not possible because of the very complex aerosol scenario and the large number of assumptions and critical LIRIC input parameters.

It is too early to draw general conclusions from the LIRIC studies done so far in the framework of EARLINET and ACTRIS activities. More scenarios with very different aerosol loadings, layering, and mixing including aerosol types from marine, over urban and biomass-burning aerosol, to mineral and volcanic dust must be analyzed and discussed in order to further improve the synergistic lidar-photometer analysis techniques. Other particle shape models may be developed and tested to better reproduce the $180^{\circ}$ scattering properties of irregularly shaped particles. Much more work of comparisons of LIRIC results, Raman lidar products, and also independent airborne in situ aerosol observations would be desirable. But in situ observations often suffer from inlet problems (cutoff prohibits that large particles are detected) and that particles are measured under dry rather than ambient humidity conditions.

Nevertheless, the presented two case studies demonstrate that LIRIC is a powerful and promising tool for the retrieval of optical and microphysical aerosol properties. As raw and ready-to-use elastic-backscatter lidar signals that serve as input for the algorithm and photometric measurements are available through the AERONET website, an almost instantaneous and fast data analysis is possible. An automated version of LIRIC is currently under development.

Acknowledgements. The research leading to these results has been performed in the framework of ACTRIS Workpackage 20 (ACTRIS Joint Research Activity "Lidar and sun photometer") and received funding from the European Union Seventh Framework Programme (FP7/2007-2013) under grant agreement no. 262254. Discussion within ACTRIS Workpackage 20 is gratefully acknowledged.

Edited by: V. Amiridis

\section{References}

Ansmann, A., Wandinger, U., Riebesell, M., Weitkamp, C., and Michaelis, W.: Independent measurement of extinction and backscatter profiles in cirrus clouds by using a combined Raman elastic-backscatter lidar, Appl. Optics, 31, 7113-7131, 1992.

Ansmann, A., Wagner, F., Müller, D., Althausen, D., Herber, A., von Hyoningen-Huene, W., and Wandinger, U.: European pollution outbreaks during ACE 2: Optical particle properties inferred from multiwavelength lidar and star-Sun photometry, J. Geophys. Res., 107, AAC 8.1-AAC 8.14, doi:10.1029/2001JD001109, 2002.

Ansmann, A., Tesche, M., Seifert, P., Groß, S., Freudenthaler, V., Apituley, A., Wilson, K. M., Serikov, I., Linné, H., Heinold, B., Hiebsch, A., Schnell, F., Schmidt, J., Mattis, I., Wandinger, U., and Wiegner, M.: Ash and fine-mode particle mass profiles from EARLINET-AERONET observations over central Europe after the eruptions of the Eyjafjallajökull volcano in 2010, J. Geophys. Res., 116, D00U02, doi:10.1029/2010JD015567, 2011a.

Ansmann, A., Petzold, A., Kandler, K., Tegen, I., Wendisch, M., Müller, D., Weinzierl, B., Müller, T., and Heintzenberg, J.: Saharan Mineral Dust Experiment SAMUM-1 and SAMUM-2: what have we learned?, Tellus B, 63, 403-429, doi:10.1111/j.16000889.2011.00555.x, 2011b.

Ansmann, A., Seifert, P., Tesche, M., and Wandinger, U.: Profiling of fine and coarse particle mass: case studies of Saharan dust 
and Eyjafjallajökull/Grimsvötn volcanic plumes, Atmos. Chem. Phys., 12, 9399-9415, doi:10.5194/acp-12-9399-2012, 2012.

Böckmann, C., Miranova, I., Müller, D., Scheidenbach, L., and Nessler, R.: Microphysical aerosol parameters from multiwavelength lidar, J. Opt. Soc. Am. A, 22, 518-528, 2005.

Chaikovsky, A., Dubovik, O., Goloub, P., Balashevich, N., Lopatsin, A., Karol, Y., Denisov, S., and Lapyonok, T.: Software package for the retrieval of aerosol microphysical properties in the vertical column using combined lidar/photometer data (test version), Tech. rep., Institute of Physics, National Academy of Sciences of Belarus, Minsk, Belarus, 2008.

Chaikovsky, A., Dubovik, O., Goloub, P., Tanré, D., Pappalardo, G., Wandinger, U., Chaikovskaya, L., Denisov, S., Grudo, Y., Lopatsin, A., Karol, Y., Lapyonok, T., Korol, M., Osipenko, F., Savitski, D., Slesar, A., Apituley, A., Arboledas, L. A., Binietoglou, I., Kokkalis, P., Granados Muñoz, M. J., Papayannis, A., Perrone, M. R., Pietruczuk, A., Pisani, G., Rocadenbosch, F., Sicard, M., De Tomasi, F., Wagner, J., and Wang, X.: Algorithm and software for the retrieval of vertical aerosol properties using combined lidar/ radiometer data: Dissemination in EARLINET, in: Proceedings of the 26th International Laser and Radar Conference, vol. 1, Porto Heli, Greece, 25-29 June 2012, 399-402, 2012.

Dubovik, O.: Optimization of numerical inversion in photopolarimetric remote sensing, in: Photopolarimetry in Remote Sensing, edited by: Videen, G., Yatskiv, Y., and Mishchenko, M., 65106, Kluwer Academic Publishers, Dordrecht, The Netherlands, 2004.

Dubovik, O. and King, M. D.: A flexible inversion algortihm for retrieval of aerosol optical properties from Sun and sky radiance measurements, J. Geophys. Res., 105, 20673-20696, 2000.

Dubovik, O., Holben, B. N., Lapyonok, T., Sinyuk, A., Mishchenko, M. I., Yang, P., and Slutsker, I.: Non-spherical aerosol retrieval method employing light scattering by spheroids, Geophys. Res. Lett., 29, 1415, doi:10.1029/2001GL014506, 2002.

Dubovik, O., Sinyuk, A., Lapyonok, T., Holben, B. N., Mishchenko, M., Yang, P., Eck, T. F., Volten, H., Munoz, O., Weihelmann, B., van der Zande, W. J., Leon, J.-F., Sokorin, M., and Slutsker, I.: Application of spheroid models to account for aerosol particle nonspericity in remote sensing of desert dust, J. Geophys. Res., 11, D11208, doi:10.1029/2005JD006619, 2006.

Eadie, W. T. D., Drijard, D., James, F. E., Roos, M., and Sadoulet, B.: Statistical Methods in Experimental Physics, North-Holland Publishing Company, Amsterdam, London, 1971.

Gasteiger, J., Wiegner, M., Groß, S., Freudenthaler, V., Toledano, C., Tesche, M., and Kandler, K.: Modelling lidar-relevant optical properties of complex mineral dust aerosols, Tellus B, 63, 725741, doi:10.1111/j.1600-0889.2011.00559.x, 2011a.

Holben, B. N., Eck, T. F., Slutsker, I., Tanré, D., Buis, J. P., Setzer, A., Vermote, E., Reagan, J. A., Kaufman, Y. J., Nakajima, T., Lavenu, F., Jankowiak, I., and Smirnov, A.: AERONET - A federated instrument network and data archive for aerosol characterization, Remote Sens. Environ., 66, 1-16, 1998.

Kaufman, Y., Tanré, D., Léon, J.-F., and Pelon, J.: Retrievals of profiles of fine and coarse aerosols using lidar and radiometric space measurements, IEEE T. Geosci. Remote Sens., 41, 1743-1754, 2003a.

Kaufman, Y. J., Haywood, J. M., Hobbs, P. V., Hart, W., Kleidman, R., and Schmid, B.: Remote sensing of vertical distributions of smoke aerosol off the coast of Africa, Geophys. Res. Lett., 30, 1831, doi:10.1029/2003GL017068, 2003b.

Lathem, T. L., Kumar, P., Nenes, A., Dufek, J., Sokolik, I. N., Trail, M., and Russell, A.: Hygroscopic properties of volcanic ash, Geophys. Res. Lett., 38, L11802, doi:10.1029/2011GL047298, 2011.

Léon, J.-F., Tanré, D., Pelon, J., Kaufman, Y. J., Haywood, J. M., and Chatenet, B.: Profiling of a Saharan dust outbreak based on a synergy between active and passive remote sensing, J. Geophys. Res., 108, 8575, doi:10.1029/2002JD002774, 2003.

Lopatin, A., Dubovik, O., Chaikovsky, A., Goloub, Ph., Lapyonok, T., Tanré, D., and Litvinov, P.: Enhancement of aerosol characterization using synergy of lidar and sun - photometer coincident observations: the GARRLiC algorithm, Atmos. Meas. Tech. Discuss., 6, 2253-2325, doi:10.5194/amtd-6-2253-2013, 2013.

Mattis, I., Ansmann, A., Müller, D., Wandinger, U., and Althausen, D.: Multiyear aerosol observations with dual-wavelength Raman lidar in the framework of EARLINET, J. Geophys. Res., 109, D13203, doi:10.1029/2004JD004600, 2004.

Müller, D., Wandinger, U., and Ansmann, A.: Microphysical particle parameters from extinction and backscatter lidar data by inversion with regularization: Theory, Appl. Optics, 38, 23462357, 1999.

Müller, D., Mattis, I., Wandinger, U., Ansmann, A., Althausen, D., and Stohl, A.: Raman lidar observations of aged Siberian and Canadian forest fire smoke in the free troposphere over Germany in 2003: Microphysical particle characterization, J. Geophys. Res., 110, D17201, doi:10.1029/2004JD005756, 2005.

Müller, D., Ansmann, A., Mattis, I., Tesche, M., Wandinger, U., Althausen, D., and Pisani, G.: Aerosol-type-dependent lidar ratios observed with Raman lidar, J. Geophys. Res., 112, D16202, doi:10.1029/2006JD008292, 2007.

Müller, D., Ansmann, A., Freudenthaler, V., Kandler, K., Toledano, C., Hiebsch, A., Gasteiger, J., Esselborn, M., Tesche, M., Heese, B., Althausen, D., Weinzierl, B., Petzold, A., and von Hoyningen-Huene, W.: Mineral dust observed with AERONET Sun photometer, Raman lidar and in situ instruments during SAMUM 2006: Shape-dependent particle properties, J. Geophys. Res., 115, D11207, doi:10.1029/2009JD012523, 2010.

Müller, D., Lee, K.-H., Gasteiger, J., Tesche, M., Weinzierl, B., Kandler, K., Müller, T., Toledano, C., Otto, S., Althausen, D., and Ansmann, A.: Comparison of optical and microphysical properties of pure Saharan mineral dust observed with AERONET Sun photometer, Raman lidar, and in situ instruments during SAMUM 2006, J. Geophys. Res., 117, D07211, doi:10.1029/2011JD016825, 2012.

Müller, D., Veselovskii, I., Kolgotin, A., Tesche, M., Ansmann, A., and Dubovik, O.: Vertical profiles of pure dust and mixed smoke-dust plumes inferred from inversion of multiwavelength Raman/polarization lidar data and comparison to AERONET retrievals and in situ observations, Appl. Optics, 52, 3178-3202, 2013.

Nicolae, D., Nemuc, A., Müller, D., Talianu, C., Vasilescu, J., Belegante, L., and Kolgotin, A.: Characterization of fresh and aged biomass burning events using multiwavelength Raman lidar and mass spectrometry, J. Geophys. Res., 118, 2956-2965, doi:10.1002/jgrd.50324, 2013.

O’Neill, N. T., Eck, T. F., Smirnov, A., Holben, B. N., and Thulasiraman, S.: Spectral discrimination of coarse and fine mode optical 
depth, J. Geophys. Res., 108, 4559, doi:10.1029/2002JD002975, 2003.

Schumann, U., Weinzierl, B., Reitebuch, O., Schlager, H., Minikin, A., Forster, C., Baumann, R., Sailer, T., Graf, K., Mannstein, H., Voigt, C., Rahm, S., Simmet, R., Scheibe, M., Lichtenstern, M., Stock, P., Rüba, H., Schäuble, D., Tafferner, A., Rautenhaus, M., Gerz, T., Ziereis, H., Krautstrunk, M., Mallaun, C., Gayet, J.F., Lieke, K., Kandler, K., Ebert, M., Weinbruch, S., Stohl, A., Gasteiger, J., Groß, S., Freudenthaler, V., Wiegner, M., Ansmann, A., Tesche, M., Olafsson, H., and Sturm, K.: Airborne observations of the Eyjafjalla volcano ash cloud over Europe during air space closure in April and May 2010, Atmos. Chem. Phys., 11, 2245-2279, doi:10.5194/acp-11-2245-2011, 2011.

Schuster, G. L., Vaughan, M., MacDonnell, D., Su, W., Winker, D., Dubovik, O., Lapyonok, T., and Trepte, C.: Comparison of CALIPSO aerosol optical depth retrievals to AERONET measurements, and a climatology for the lidar ratio of dust, Atmos. Chem. Phys., 12, 7431-7452, doi:10.5194/acp-12-7431-2012, 2012.

Sugimoto, N., Uno, I., Nishikawa, M., Shimizu, A., Matsui, I., Dong, X., Chen, Y., and Quan, H.: Record heavy Asian dust in Beijing in 2002: Observations and model analysis of recent events, Geophys. Res. Lett., 30, 1640, doi:10.1029/2002GL016349, 2003.

Tesche, M., Ansmann, A., Müller, D., Althausen, D., Engelmann, R., Freudenthaler, V., and Groß, S.: Separation of dust and smoke profiles over Cape Verde by using multiwavelength Raman and polarization lidars during SAMUM 2008, J. Geophys. Res., 114, D13202, doi:10.1029/2009JD011862, 2009a.
Tesche, M., Ansmann, A., Müller, D., Althausen, D., Mattis, I., Heese, B., Freudenthaler, V., Wiegner, M., Esselborn, M., Pisani, G., and Knippertz, P.: Vertical profiling of Saharan dust with Raman lidars and airborne HSRL in southern Morocco during SAMUM, Tellus B, 61, 144-164, 2009b.

Veselovskii, I., Kolgotin, A., Griaznov, V., Müller, D., Wandinger, U., and Whiteman, D. N.: Inversion with regularization for the retrieval of tropospheric aerosol parameters from mulitwavelength lidar sounding, Appl. Optics, 41, 3685-3699, 2002.

Veselovskii, I., Dubovik, O., Kolgotin, A., Lapyonok, T., Girolamo, P. D., Summa, D., Whiteman, D. N., Mishchenko, M., and Tanré, D.: Application of randomly oriented spheroids for retrieval of dust particle parameters from multiwavelength lidar measurements, J. Geophys. Res., 115, D21203, doi:10.1029/2010JD014139, 2010.

Volten, H., Munoz, O., Rol, E., deHaan, J. F., Vassen, W., Hovenier, J. W., Muinonen, K., and Nousiainen, T.: Scattering matrices of mineral aerosol particles at $441.6 \mathrm{~nm}$ and $632.8 \mathrm{~nm}$, J. Geophys. Res., 106, 17375-17401, doi:10.1029/2001JD900068, 2001.

Wagner, J.: Microphysical properties retrieved from combined lidar sun photometer measurements, University Master Thesis, Universität Leipzig, Germany, Sächsische Landesbibliothek Staats- und Universitätsbibliothek Dresden, available at: http:// nbn-resolving.de/urn:nbn:de:bsz:15-qucosa-99830 (last access: 15 July 2013), 2012.

Wandinger, U. and Ansmann, A.: Experimental determination of the lidar overlap profile with Raman lidar, Appl. Optics, 41, 511514, 2002. 